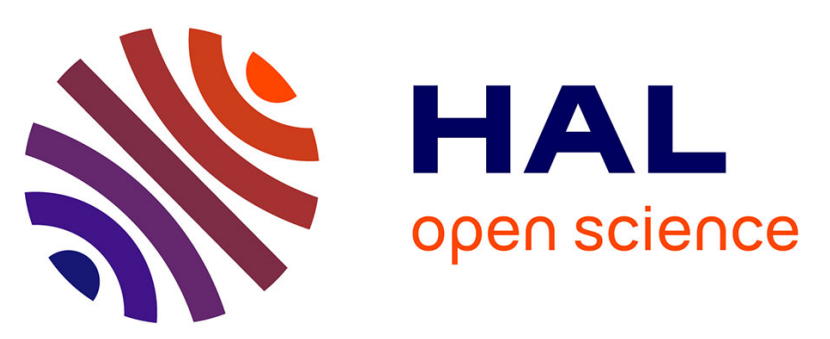

\title{
Innovative Method for Laponite Encapsulation into Polymer Latex Particles by Clay Cluster-Seeded Emulsion Polymerization
}

\author{
Laura Delafresnaye, Pierre-Yves Dugas, Muriel Lansalot, Elodie
}

Bourgeat-Lami

\section{To cite this version:}

Laura Delafresnaye, Pierre-Yves Dugas, Muriel Lansalot, Elodie Bourgeat-Lami. Innovative Method for Laponite Encapsulation into Polymer Latex Particles by Clay Cluster-Seeded Emulsion Polymerization. Macromolecules, 2019, 53 (1), pp.39-50. 10.1021/acs.macromol.9b02190 . hal-02493712

\section{HAL Id: hal-02493712 \\ https://hal.science/hal-02493712}

Submitted on 12 Nov 2020

HAL is a multi-disciplinary open access archive for the deposit and dissemination of scientific research documents, whether they are published or not. The documents may come from teaching and research institutions in France or abroad, or from public or private research centers.
L'archive ouverte pluridisciplinaire HAL, est destinée au dépôt et à la diffusion de documents scientifiques de niveau recherche, publiés ou non, émanant des établissements d'enseignement et de recherche français ou étrangers, des laboratoires publics ou privés. 


\title{
Innovative method for Laponite encapsulation into polymer latex particles by clay cluster-seeded emulsion polymerization
}

Laura Delafresnaye,,$^{\dagger}$ Pierre-Yves Dugas,,$^{\dagger}$ Muriel Lansalot,,$^{\dagger^{*}}$ Elodie Bourgeat-Lami ${ }^{{ }^{*}}$

${ }^{\dagger}$ Univ Lyon, Université Claude Bernard Lyon 1, CPE Lyon, CNRS, UMR 5265, Chemistry, Catalysis, Polymers \& Processes (C2P2), 43 Bvd. du 11 Novembre 1918, 69616 Villeurbanne, France

\begin{abstract}
We herein report an innovative pathway for the encapsulation of Laponite ${ }^{\circledR}$ platelets into polymer nanoparticles via free radical polymerization in heterogeneous aqueous medium. Hydrophobization of the Laponite ${ }^{\circledR}$ platelets was performed via double functionalization of the clay basal surfaces and edges by a cationic surfactant and an organosilane, respectively. The hydrophobized platelets were then dispersed in toluene and ultrasonicated with an aqueous solution of an anionic surfactant to form clay-loaded toluene droplets. The droplets were subsequently transformed into clusters by toluene evaporation and finally encapsulated into polymer latex particles using a seeded-emulsion polymerization process. Two different copolymers were synthesized: poly(styrene-co-methyl acrylate), as a model system, and poly(vinylidene chloride-co-methyl acrylate), a specialty film-forming copolymer. Stable composite particles with a diameter ranging from 150 to $180 \mathrm{~nm}$ were obtained for both copolymers. TEM analysis showed that the Laponite ${ }^{\circledR}$ clay platelets were successfully encapsulated into the polymer latex particles. The films cast from the composite suspensions of poly(vinylidene chloride-co-methyl acrylate)/clay particles showed spherical inclusions of clay tactoids dispersed within the polymer matrix.
\end{abstract}




\section{INTRODUCTION}

In the past decades, nanocomposites have generated a significant amount of attention. ${ }^{1}$ These materials ingeniously take advantage of the synergy between a polymer matrix and nanoscale fillers, leading to better mechanical, ${ }^{2,3}$ thermal $^{4,5}$ or barrier properties when compared to pure polymers, even for low filler volume fractions. ${ }^{6-8}$ Among the large variety of filler materials, layered silicates (i.e. clays) like Montmorillonite $(\mathrm{MMT})^{9}$ or Kaolinite ${ }^{10}$ are of particular interest. The introduction of fully exfoliated clay platelets acting as physical obstacles slows down the diffusion of gases, leading to a lower permeability and enhanced barrier properties. $^{11-13}$ Several methods have been reported to produce polymer-clay nanocomposites ${ }^{14}$ such as melt intercalation and in situ polymerization. ${ }^{15-17}$ Since clay platelets can be efficiently exfoliated in water, polymer/clay nanocomposites can also be synthesized through emulsion ${ }^{18}$ or miniemulsion ${ }^{19-21}$ polymerization. The obtained composite particles can be further processed into nanostructured film materials with enhanced properties. $^{22}$ While hydrophilic clay platelets most often lead to armored ${ }^{23}$ or dumbbell-like $^{24}$ morphologies, the encapsulation of clays into polymer latexes requires the clay platelets to be functionalized in order to favour polymer formation at their surface and good compatibility with the polymer matrix. ${ }^{19}$ In terms of water vapour barrier properties, adding a hydrophobic filler can further slow down the diffusion of water molecules into the material. Emulsion polymerization of styrene and acrylates in the presence of organoclays has been reported by a number of research groups. ${ }^{25}$ Miniemulsion polymerization has also been widely employed. ${ }^{19}$ In this case, the clay platelets are rendered hydrophobic prior to polymerization, typically through ionic exchange of the sodium interlayer cations with alkyl ammonium cations. The migration of the inorganic platelets in the aqueous phase is then limited by its surface tension, which is higher with water than with the monomer or the polymer. After dispersion of the 
inorganic platelets in the monomer droplets - usually by ultrasonication - polymerization takes place in submicron monomer droplets, and ideally, each polymer particle is a copy of the monomer droplets. Clay encapsulation by this technique remains however challenging since, even if the clay platelets are hydrophobic, they most often tend to aggregate at the monomer/water interface as shown in both experimental and computational studies. ${ }^{26,27,28}$ Besides, successful dispersion into the monomer phase does not guarantee that the inorganic particles are compatible with the polymer. For instance, Sun et al. ${ }^{29}$ reported the incorporation of $5 \mathrm{wt} \%$ of Laponite modified by cetyltrimethylammonium bromide into polystyrene (PSty) particles. Although the cationic surfactant enabled successful dispersion of the organoclay into styrene, the platelets were able to migrate to the particle/water interface during particle formation owing to their insufficient compatibility with the hydrophobic polymer. Employing a reactive cationic surfactant, namely vinylbenzyldodecyl dimethylammonium chloride, Zengeni et al. ${ }^{30}$ were however capable to encapsulate Laponite clay platelets into PSty particles thanks to the formation of covalent bonds with the growing polymer chains, which restrained its mobility and prevented clay migration during polymer formation. A similar approach involving dual-functionalized Laponites was reported by Faucheu et al. ${ }^{31}$ A cationic surfactant with two aliphatic chains (didodecyldimethylammonium bromide: DDAB) was chosen to promote clay exfoliation in the monomer mixture while the edges of the platelets were modified with a polymerizable silane monomer. The resulting clay platelets with edge bound methacrylate units, were successfully encapsulated into film-forming poly(methyl methacrylate-co-butyl acrylate) latex particles.

Another promising strategy relies on the use of reversible-deactivation radical polymerization (RDRP). ${ }^{32,33,34,35}$ In this approach, polymer chains synthesized by RDRP are adsorbed on the surface of the clay platelets. These chains contain a reactivatable functionality and are therefore able to grow on the surface of the inorganic particles leading to their encapsulation. 
Leaning on this strategy, Mballa Mballa et al. ${ }^{36}$ and Bourgeat-Lami and coworkers ${ }^{37,38,39}$ succeeded in encapsulating $\mathrm{MMT}^{36,37}$ and layered double hydroxide ${ }^{38,39}$ clay platelets using a series of amphiphilic random copolymers obtained by reversible addition-fragmentation chain transfer-mediated emulsion polymerization.

As mentioned previously, introducing hydrophobic clay platelets into a polymer matrix can considerably enhance its barrier properties. With this in mind, the purpose of the present work was to develop a high barrier performance polymer by encapsulating clay platelets into poly(vinylidene chloride) (PVDC) particles, a film-forming polymer already well-known for its very good barrier properties towards water vapour and gases (notably oxygen). The excellent barrier properties of PVDC are attributed to its high chlorine content and its high crystallinity. ${ }^{40,}{ }^{41}$ However, PVDC homopolymers are inherently hard and brittle, and thus challenging to process. To overcome this issue, VDC is usually copolymerized with monomers like MA, leading to a better processability. Industrially, those copolymers are synthesized by emulsion or suspension polymerization. Miniemulsion polymerization is indeed not appropriate in this case as VDC is volatile (boiling point is about $\left.31.6{ }^{\circ} \mathrm{C}\right)^{41}$ as well as highly flammable, and therefore cannot be sonicated. RDRP methods could also be used to synthesize PVDC/clay composite particles, but these techniques would require the synthesis of suitable living polymers, which would make them the most complex of the methods described here, particularly from the perspective of scaling up.

In this context, we have decided to implement a new strategy to encapsulate clay platelets into PVDC particles. Our strategy leans on a bottom-up assembly approach similar to that previously reported by Paquet et al. ${ }^{42}$ for iron oxide encapsulation. Laponite $®$, a synthetic smectite clay, was selected for this purpose. The clay platelets were first hydrophobized using a double modification procedure involving a double alkyl chain surfactant: DDAB $\left(2 \mathrm{C}_{12}\right)$ and an alkoxysilane containing a polymerizable group: methacryloyloxypropyl trimethoxysilane 
(MPTMS) (Figure 1). ${ }^{31}$ The organoclay was then dispersed in toluene and ultrasonicated with an aqueous solution of a disulfonate anionic surfactant (Dowfax ${ }^{\circledR} 2 \mathrm{~A} 1$, Scheme $\mathrm{S} 1$ in the Supporting Information) to form a stable emulsion. Solvent evaporation confined the platelets into clusters that were subsequently used as seeds to grow a polymer shell on their surface through emulsion polymerization. Two monomers were evaluated, first styrene (Sty) as a model monomer with low water solubility $\left(0.3 \mathrm{~g} \mathrm{~L}^{-1}\right)$, and then VDC as a specialty monomer. MA was chosen as a comonomer to prepare $\mathrm{P}(\mathrm{VDC}-\mathrm{co}-\mathrm{MA})$ latexes (VDC/MA $=90 / 10$ $\mathrm{wt} / \mathrm{wt}$ ) able to form films at room temperature. In order to compare Sty and VDC, MA was also used with Sty at the same ratio. Lastly, the morphology of the P(VDC-co-MA) nanocomposite films was investigated.
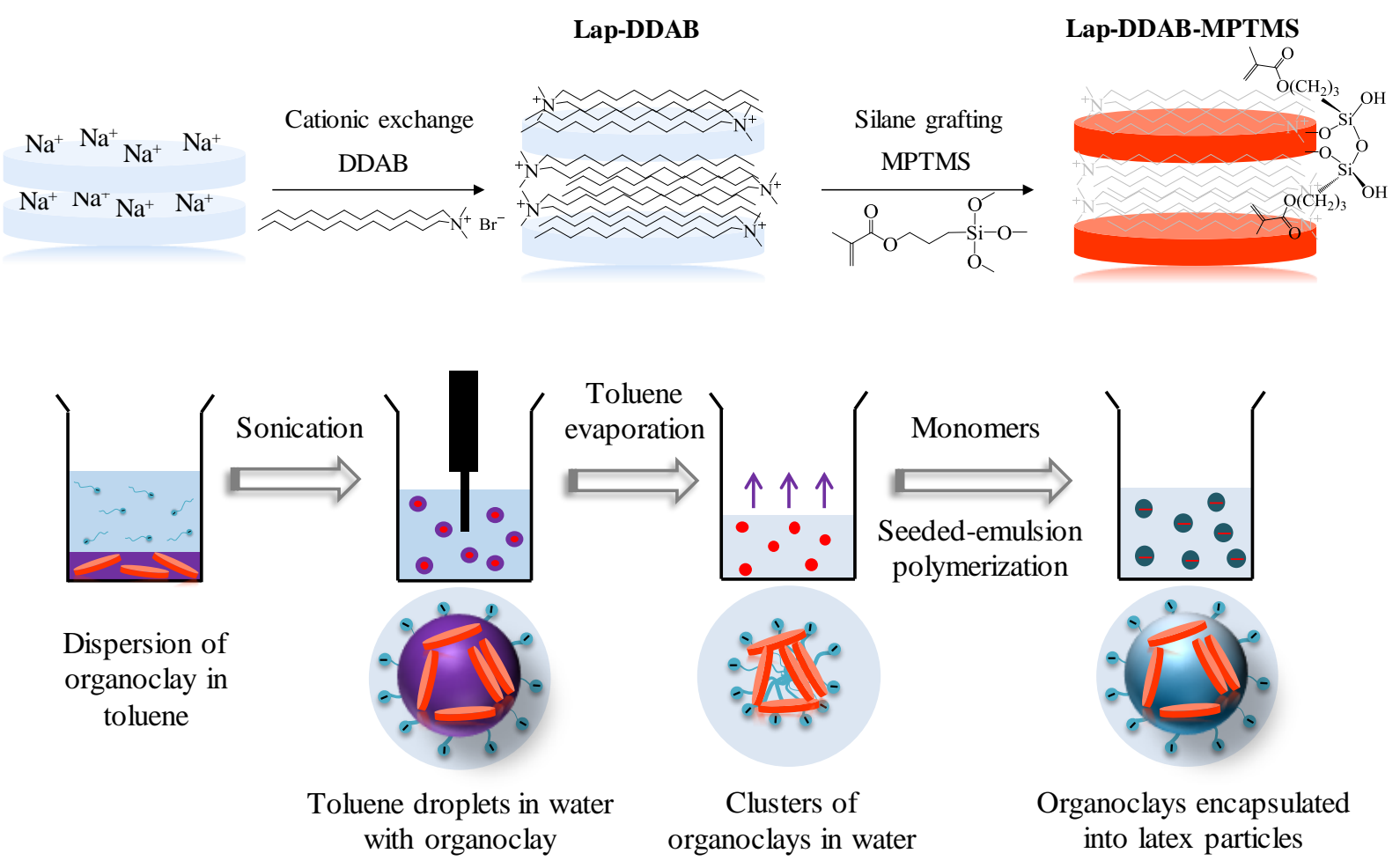

Figure 1. Global strategy for the formation of Laponite clusters and their encapsulation into polymer latex particles via seeded emulsion polymerization (not to scale). 


\section{EXPERIMENTAL}

\section{Materials}

Vinylidene chloride (VDC, Fluka, 99.5\%) was washed with a 25 wt\% aqueous $\mathrm{NaOH}$ solution and dried on $\mathrm{MgSO}_{4}$ before use. Methyl acrylate (MA, Aldrich, > 99\%) was vacuum distilled before use. Styrene (Sty, Sigma-Aldrich, 99\%), ammonium persulfate (APS, Acros Organics, 98\%), DDAB (Acros Organics, 99\%), MPTMS (Gelest Inc), toluene (Aldrich) and Dowfax ${ }^{\circledR} 2 \mathrm{~A} 1$ (Alkyldiphenyloxide disulfonate, Dow Chemical, solution at $486 \mathrm{~g} \mathrm{~L}^{-1}$ ) were all used as received. Laponite ${ }^{\circledR}$ RD and Laponite ${ }^{\circledR}$ S482 were kindly supplied by BYK Additives. Both are trioctahedral synthetic hectorites composed of two tetrahedral silica sheets and a central octahedral magnesia sheet $\left(\mathrm{Mg}^{2+}\right)$. The discoid platelets have a mean diameter of $25-30 \mathrm{~nm}$ and a thickness of $1 \mathrm{~nm}$. Laponite ${ }^{\circledR} \mathrm{RD}$ is a gel forming grade whereas Laponite ${ }^{\circledR}$ S482 is a permanent sol-grade containing 1-hydroxyethylidene bisphosphonate $\left(\mathrm{C}_{2} \mathrm{H}_{8} \mathrm{O}_{7} \mathrm{P}_{2.4} \mathrm{Na}\right)$ as a peptizing agent. ${ }^{43}$

\section{Clay hydrophobization}

Cation exchange. Organically modified Laponite ${ }^{\circledR} \mathrm{RD}$ or $\mathrm{S} 482$ clay platelets were prepared by adding varying amounts of DDAB to the aqueous clay dispersion, targeting 50, 100 or 200 $\%$ of the clay cation exchange capacity (CEC). ${ }^{44}$ The resulting intercalation complexes were referred to as Lap $x$-DDAB $y$ where $x$ corresponds to the Laponite ${ }^{\circledR}$ grade (RD or S482) and $y$ corresponds to the targeted CEC. In a typical experiment, $10 \mathrm{~g}$ of Laponite ${ }^{\circledR}$ were suspended in $300 \mathrm{~mL}$ of water under magnetic stirring for at least 2 hours at $600 \mathrm{rpm}$. The appropriate amount of DDAB (between 1.75 and $7 \mathrm{~g}$ ) was introduced in $150 \mathrm{~mL}$ of water, and added to the suspension. The mixture was stirred at $600 \mathrm{rpm}$ for 24 hours at room temperature. Then, 
the clay suspension was centrifuged at $15000 \mathrm{rpm}$ for 15 minutes. The supernatant solution containing residual unadsorbed cations was discarded, whereas the precipitate was extensively washed with water. The centrifugation procedure was performed 3 times in order to remove the cations and salt in excess. The clay powder was finally obtained by freeze-drying of the precipitate. The extent of cation exchange was quantified by thermogravimetric analysis (TGA) using equation S1 in the Supporting Information, and expressed as a percentage of the clay CEC using equation S2.

Silane grafting. In a typical experiment, $1 \mathrm{~g}$ of organically modified Laponite ${ }^{\circledR}$ was suspended in $20 \mathrm{~mL}$ of toluene and the silane was introduced at a concentration of $4.0 \mathrm{mmol}$ $\mathrm{g}^{-1}$ (based on raw Laponite $\AA$ ). The mixture was stirred for 4 days and used directly for cluster preparation. The resulting clay was labelled Lap $x$-DDABy-MPTMS. For characterization purposes, the organoclay was purified three times by centrifugation at $15000 \mathrm{rpm}$ for 15 minutes and redispersion into toluene, dried under vacuum (rotary evaporator) and characterized by TGA. The silane grafting density and the grafting yield were then determined from the weight loss between 150 and $600{ }^{\circ} \mathrm{C}$ using equations S3 and S4, respectively (Supporting Information).

\section{Cluster formation}

In a typical experiment, a $125 \mathrm{~mL}$ solution of Dowfax ${ }^{\circledR} 2 \mathrm{~A} 1\left(1\right.$ to $\left.5 \mathrm{~g} \mathrm{~L}^{-1}\right)$ was added to 20 $\mathrm{mL}$ of a $50 \mathrm{~g} \mathrm{~L}^{-1}$ organo-modified clay suspension in toluene. The solution, consisting of two immiscible phases, was placed in an ice bath and the sonication time was set to 5 minutes with 20 seconds pulse on and 20 seconds pulse off to prevent overheating $(750 \mathrm{~W}, 80 \%)$. Toluene was removed from the obtained miniemulsion with a rotary evaporator $\left(80{ }^{\circ} \mathrm{C}, 450\right.$ mbar) confining the clay platelets into clusters. The cluster concentration ( 2 to $5 \mathrm{wt} \%$ ) was determined by gravimetric analysis. 


\section{Particle synthesis}

$P\left(\right.$ Sty-co-MA)/Laponite ${ }^{\circledR}$. In a typical experiment (run P2, Figure 3), the cluster suspension (95 g) was introduced in a double-jacketed glass reactor, purged with nitrogen for 20 minutes with a stirring rate fixed at $300 \mathrm{rpm}$, and then heated at $70{ }^{\circ} \mathrm{C}$. When this temperature was reached, $18.0 \mathrm{~g}(0.173 \mathrm{~mol})$ of styrene and $2.0 \mathrm{~g}(0.023 \mathrm{~mol})$ of MA (previously deoxygenated) were introduced. A deoxygenated solution of APS $(0.47 \mathrm{mmol})$ in water $(5 \mathrm{~g})$ was then injected (time zero). Samples were periodically withdrawn to measure the overall monomer weight conversion by gravimetric analysis, along with the particle size and the particle size distribution by dynamic light scattering (DLS).

$P\left(V D C\right.$-co-MA)/Laponite ${ }^{\circledR}$. In a typical experiment (run P4, Table 4), APS (0.47 mmol) was dissolved in $5 \mathrm{~g}$ of water and added to the cluster suspension $(95 \mathrm{~g})$. The mixture was then introduced in a pressurized double-jacketed glass reactor (Parr Instrument Company) and purged with nitrogen for 20 minutes. After deoxygenation of monomers by nitrogen bubbling for 20 minutes, $2.1 \mathrm{~mL}(0.023 \mathrm{~mol})$ of MA and $14.8 \mathrm{~mL}(0.186 \mathrm{~mol})$ of VDC were introduced via the injection valve into the reactor (time zero). The autoclave was pressurized at 1 bar with nitrogen and connected to a pre-heated water bath. The reaction mixture was stirred with an anchor at $300 \mathrm{rpm}$ and heated at $70{ }^{\circ} \mathrm{C}$ (the pressure raised to 4 bar). After 1 hour, the stirring rate was decreased to $100 \mathrm{rpm}$. The reaction was stopped when the pressure came back to 1 bar. The autoclave was then depressurized and the residual monomers stripped with nitrogen under gentle stirring during 1 hour. The final latex (after stripping) was characterized as described above for $\mathrm{P}(\mathrm{Sty}-\mathrm{co}-\mathrm{MA}) /$ Laponite ${ }^{\circledR}$ latexes. However, no kinetic study was carried out for the VDC-based latexes. Indeed, as the polymerization was conducted in a pressurized reactor (4 bar), it was not possible to withdraw samples. 


\section{Film-formation}

Free-standing films were obtained by casting $\mathrm{P}(\mathrm{VDC}-$-co-MA $) /$ Laponite latexes into a silicon mold $(4 \times 3 \mathrm{~cm})$ and left to dry for 24 hours at ambient temperature.

\section{Characterization techniques}

Dynamic light scattering (DLS). The hydrodynamic diameter of the particle $\left(\mathrm{D}_{\mathrm{h}}\right)$ and the broadness of the size distribution (i.e. the dispersity, PdI) were determined using a Zetasizer Nano ZS from Malvern Instruments $\left(25^{\circ} \mathrm{C}, \lambda=633 \mathrm{~nm}\right.$, angle $\left.=173^{\circ}\right)$. Samples were prepared by diluting 1 droplet of latex in $2 \mathrm{~mL}$ of Milli-Q water and the data were collected using the fully automatic mode of the Zetasizer system and fitted with cumulant analysis. The number of particles per liter of latex, $\mathrm{N}_{\mathrm{p}}\left(\mathrm{L}^{-1}\right)$, at the end of the polymerization was calculated from $D_{h}$ according to the equation:

$$
\mathbf{N}_{\mathbf{p}}=\frac{\mathrm{C}_{\text {polymer(composite) }} \times \mathbf{6} \times 10^{21}}{\rho_{\text {polymer(composite) }} \times \pi \times \mathrm{D}_{\mathrm{h}}{ }^{3}} \quad \text { Equation } 1
$$

where $\mathrm{C}_{\text {polymer(composite) }}\left(\mathrm{g} \mathrm{L}^{-1}\right)$ and $\rho_{\text {polymer(composite) }}\left(\mathrm{g} \mathrm{cm}^{-3}\right)$ are the concentration (determined from the monomer conversion) and the density of the polymer (respectively composite) latex particles.

Electron microscopy. Electron microscopy analyses were carried out at the Centre Technologique des Microstructures (CT $\mu$ ), platform of the Université Claude Bernard Lyon 1, Villeurbanne, France. A drop of the diluted latexes was deposited on a carbon/Formvarcoated copper grid and the solvent was allowed to evaporate. Samples were observed by transmission electron microscopy (TEM) at room temperature with a Philips CM120 microscope operating at an accelerating voltage of $80 \mathrm{kV}$. The same procedure was used with carbon grids (200 mesh) for high-resolution TEM (HR-TEM) and high-angle annular dark- 
field-scanning transmission electron microscopy (HAADF-STEM). These analyses were performed with a JEOL $2100 \mathrm{~F}$ high-resolution microscope operating at an accelerating voltage of $200 \mathrm{kV}$. The specimen holder was tilted at $15^{\circ}$ (with respect to the energydispersive detector). In order to preserve particle shape, some latexes were also observed in their natural hydrated environment using cryogenic TEM (cryo-TEM). The diluted samples were dropped onto 300 Mesh holey carbon films (Quantifoil R2/1), and quench-frozen in liquid ethane. Samples were transferred in the microscope (Phillips CM120) using a precooled Gatan 626 specimen holder, and observed at an accelerating voltage of $120 \mathrm{kV}$. Thin crosssections of $\mathrm{P}(\mathrm{VDC}-\mathrm{co}-\mathrm{MA}) / \mathrm{clay}$ films were observed by TEM. The thin foil TEM specimens $(<100 \mathrm{~nm})$ were prepared using a diamond knife on a cryo-ultramicrotome equipment.

pH measurements. The $\mathrm{pH}$ values of the latexes were measured with a Mettler Toledo SevenEasy pH-meter using an InLab Science Pro electrode calibrated with pH 4.01, 7.00, and 10.00 buffer solutions from Mettler Toledo.

Thermogravimetric analysis (TGA). TGA measurements were performed with a thermogravimeter Mettler Toledo TGA/DSC1 instrument. $10 \mathrm{mg}$ of the organoclay were introduced in a weighted ceramic crucible and then inserted in the oven at $25{ }^{\circ} \mathrm{C}$. The temperature was raised to $700{ }^{\circ} \mathrm{C}$ at $\mathrm{a}+10{ }^{\circ} \mathrm{C} \min ^{-1}$ rate and the sample mass was constantly followed in order to monitor the weight loss caused by product degradation and/or removal of volatile compounds.

Fourier-transform infrared (FTIR) spectroscopy. FTIR spectra were collected with a Nicolet iS50 FT-IR spectrometer (Thermo Scientific). Clay powders were directly placed under the ATR detector and the spectra were processed using the Omnic software.

Wide-angle X-ray scattering (WAXS). WAXS measurements were carried out at the BM02 beamline of the European Synchrotron Radiation Facilities (ESRF, Grenoble, France). 
Experiments were carried out at an energy of $25.5 \mathrm{keV}$ with a sample-to-detector distance of $16 \mathrm{~cm}$ using a $1242 \times 1152 \mathrm{CCD}$ camera. The recorded images were first corrected from dark current and flat field and normalized with respect to the intensity of the incident beam. The azimuthal integration of the corrected images gave the radial integration (scattering curves). Finally, the obtained scattering curves were calibrated (q-axis) using silver behenate and corrected for sample transmission and background subtraction. Scattering angle $2 \theta$ and basal spacings $d_{001}$ were calculated using the Bragg's law $(n=1)$ and the $C u K_{\alpha}$ radiation $(\lambda=$ $1.5406 \AA$ ).

\section{RESULTS AND DISCUSSION}

\section{Clay hydrophobization}

To help disperse the Laponite ${ }^{\circledR}$ clay platelets in toluene, their basal surfaces were hydrophobized by the incorporation of long alkyl chains. A cationic surfactant with two dodecyl chains (DDAB) was selected to be exchanged with the sodium ions present in the interlayer space of two different Laponite ${ }^{\circledR}$ grades. Laponite ${ }^{\circledR}$ S482 that contains a patented peptizing agent was compared to Laponite ${ }^{\circledR} \mathrm{RD}$, a raw Laponite ${ }^{\circledR}$ without peptizing agent. Various amounts of DDAB were incorporated in order to observe the impact of the degree of hydrophobicity on clay encapsulation. The amounts of DDAB introduced corresponded to 50, 100 and $200 \%$ of the CEC of Laponite $\left(0.75 \mathrm{meq}^{-1}\right)$. The cation exchange reaction was characterized by qualitative (FTIR, WAXS) and quantitative (TGA) analyses as previously described in the literature. ${ }^{45-49}$ FTIR (Figure S1 in the Supporting Information) allowed observing three bands attributed to the presence of methylene groups from DDAB: the $v_{\mathrm{CH} 2}$ bending at $1467 \mathrm{~cm}^{-1}$ and two $v_{\mathrm{CH} 2}$ asymmetric and symmetric stretchings at 2852 and 2925 $\mathrm{cm}^{-1}$, respectively. WAXS analyses of the bare and organomodified Laponite ${ }^{\circledR}$ samples 
confirmed DDAB intercalation into the clay galleries (Figure S3 and Table S1 in the Supporting Information). The peak corresponding to the basal plane 001 was displaced to a lower angle indicating an extension of the interlamellar space. Similar FTIR and WAXS results were obtained for Laponite ${ }^{\circledR}$ RD and Laponite S482. Furthermore, TGA analysis confirmed that the cationic exchange for both Laponite grades was quantitative for all targeted CECs in agreement with previous findings in the literature ${ }^{50}$ (Table 1 and Figure S4 in the Supporting Information). One can note that in some cases, the amount of intercalated surfactant was higher than the initial loading, which is thought to be due to clay particles with lower surface coverage being lost during the purification step, as already reported for Laponite clays treated with cationic surfactants. ${ }^{51}$

Table 1. Weight loss of bare DDAB and modified Laponite ${ }^{\circledR}$ between 150 and $600{ }^{\circ} \mathrm{C}$, and corresponding amounts of intercalated DDAB expressed in meq $\mathrm{g}^{-1}$ or as a percentage of the CEC.

\begin{tabular}{lccc}
\hline & $\begin{array}{c}\Delta \mathrm{m}_{\text {Lap-DDAB }} \\
(\%)^{\mathrm{a}}\end{array}$ & \multicolumn{2}{c}{$\mathrm{DDAB}_{\text {intercalated }}$} \\
$\left(\mathrm{meq} \mathrm{g}^{-1}\right)^{\mathrm{b}}$ & $(\% \mathrm{CEC})^{\mathrm{c}}$ \\
\hline DDAB & 97.9 & - & - \\
\hline LapS482-DDAB50 & 16.0 & 0.51 & 68 \\
LapS482-DDAB100 & 22.5 & 0.77 & 103 \\
LapS482-DDAB200 & 40.5 & 1.63 & 218 \\
\hline LapRD-DDAB100 & 21.0 & 0.72 & 96 \\
LapRD-DDAB200 & 40.5 & 1.63 & 218 \\
\hline
\end{tabular}

${ }^{\mathrm{a}}$ Weight loss of the organomodified Laponite between 150 and $600{ }^{\circ} \mathrm{C}$ determined by TGA. ${ }^{\text {b, }}{ }^{c}$ Determined using equations S1 and S2, respectively (Supporting Information).

To improve clay compatibility with the polymer phase and prevent migration of the platelets to the polymer/water interface during the polymerization reaction, reactive organosilanes ${ }^{52}$ or titanates ${ }^{25}$ can additionally be used to react with the hydroxyl groups located at the edges of the platelets. Hence, the second step was to graft a trifunctional silane, MPTMS, on Laponite ${ }^{\circledR}$ edges by a condensation reaction as previously reported by Negrete-Herrera et 
al. ${ }^{53}$ The reaction was carried out at room temperature for 4 days using a fixed MPTMS concentration of $4 \mathrm{mmol} \mathrm{g}^{-1}$ (based on raw Laponite). The resulting particles were purified by centrifugation to remove the silane in excess, and characterized by FTIR spectroscopy (Figure S2) and TGA (Figure S4). Both techniques confirmed the covalent attachment of the silane compound. The grafting yield was lower for Laponite® S482 (9.5\%, Table S2, Equation S3 and S4, ESI) than for Laponite ${ }^{\circledR} \mathrm{RD}(28.1 \%)$ likely due to the presence of the phosphonate peptizing agent that hinders accessibility to the clay edges. The grafting yield was in both cases lower than reported in the literature ${ }^{53}$ which reports $60 \%$ yield. This can likely be explained by the shorter reaction time and by the steric hindrance brought by the two alkyl chains of the intercalated DDAB, which would restrict the access to the edges.

To conclude, DDAB was successfully intercalated within the interlayer space of Laponite ${ }^{\circledR}$ and similar results were obtained for the two grades with a quantitative cation exchange. MPTMS was subsequently grafted on the edges and the grafting was more efficient for Laponite ${ }^{\circledR}$ RD than for Laponite ${ }^{\circledR}$ S482 likely due to a better accessibility of the silane molecules to the hydroxyl groups. In the following, the hydrophobized clay platelets will be used as is (i.e. without removal of the silane in excess (vide infra)) to form colloidal clusters using the emulsion droplet solvent evaporation technique.

\section{Preparation of clay-loaded toluene droplets}

The next step involved confining the clay platelets into stable clusters dispersed in water. For this purpose, the organomodified Laponite ${ }^{\circledR}$ was introduced in toluene and the resulting dispersion was emulsified with an aqueous solution of Dowfax ${ }^{\circledR} 2 \mathrm{~A} 1$, an anionic surfactant with two sulfonate heads. Evaporation of the solvent transformed the clay-loaded toluene droplets into clay clusters stabilized by surfactant, and the cluster suspension was then directly used as seed for subsequent emulsion polymerization. The emulsification step is 
crucial because it will set the droplet size and consequently the number of platelets per droplet and the size of the clusters, assuming that the clay sheets are uniformly distributed among the droplets. As mentioned above, Dowfax ${ }^{\circledR} 2 \mathrm{~A} 1$ was chosen as anionic surfactant and the quantity mentioned hereafter corresponds to the active weight. In addition, with the goal of developing a simple and effective process, no purification of the organoclay was undertaken after introduction of the silane molecule, and the ungrafted MPTMS remained free in solution. ${ }^{54}$ The efficiency of droplet formation - leading to a dispersion hereafter referred to as a miniemulsion - was investigated taking into account three parameters: the toluene content, the surfactant concentration and the hydrophobic character of the clay.

\section{Effect of toluene content}

For this first study, we set the concentration of LapS482-DDAB200-MPTMS (the most hydrophobic clay) in toluene at $50 \mathrm{~g} \mathrm{~L}^{-1}$. To vary the toluene content (from 25 to $15 \mathrm{wt} \%$ based on the overall toluene plus water weight), the amounts of toluene (20 g) and Dowfax® 2A1 ( $1 \mathrm{wt} \%$ based on toluene) were kept constant while the water volume was varied from 60 to $110 \mathrm{~mL}$ (runs M1a to M1f, Table 2). The diameter of the toluene droplets containing the clay was around $260 \mathrm{~nm}$ for the highest toluene weight fraction (i.e., $25 \mathrm{wt} \%$ ), but this diameter could be reduced to $150 \mathrm{~nm}$ when the mixture was diluted with water. A plateau was observed when the percentage of toluene in the mixture was decreased to $18 \mathrm{wt} \%$ and adding more water did not permit to decrease further the droplet size. Similarly, the polydispersity index decreased from 0.39 to 0.16 when decreasing the toluene fraction in the mixture and became stable for toluene fractions of $18 \mathrm{wt} \%$ or lower. We hypothesize that more energy is required when the oil phase volume fraction increases. In the following experiments the toluene weight fraction was thus fixed at $15 \mathrm{wt} \%$. 
Table 2. Experimental conditions and characteristics of the toluene droplets for varying weight fractions of toluene in the water/toluene mixture. ${ }^{\mathrm{a}}$

\begin{tabular}{lcccccc}
\hline Run & M1a & M1b & M1c & M1d & M1e & M1f \\
\hline Toluene $\left(w t \%\right.$ / toluene $\left.+\mathrm{H}_{2} \mathrm{O}\right)$ & 25.0 & 22.2 & 20.0 & 18.1 & 16.5 & 15.2 \\
Dowfax ${ }^{\circledR} 2 \mathrm{~A} 1\left(\mathrm{~g} \mathrm{~L}^{-1}\right.$ water $)$ & 2.6 & 2.3 & 2.1 & 1.9 & 1.7 & 1.6 \\
D $_{\text {h droplets }}(\mathrm{nm})^{\mathrm{b}}$ & 259 & 211 & 209 & 149 & 150 & 142 \\
PdI $^{\mathrm{b}}$ & 0.39 & 0.36 & 0.31 & 0.16 & 0.16 & 0.18 \\
\hline
\end{tabular}

${ }^{\mathrm{a}} 600 \mathrm{~W}, 5$ minutes by pulses of 20 seconds; LapS482-DDAB200-MPTMS: $1 \mathrm{~g} \mathrm{(} 5 \mathrm{wt} \%$ toluene); toluene: $20 \mathrm{~g}$; Dowfax ${ }^{\circledR}$ 2A1: $0.21 \mathrm{~g}$ (1.05 wt\% based on toluene or $21 \mathrm{wt} \%$ based on bare clay); MPTMS: $3 \mathrm{mmol} \mathrm{g}$ Lap- $^{-1}$ $\mathrm{DDAB} / 4 \mathrm{mmol} \mathrm{g}^{-1}{ }_{\text {bare Laponite. }}{ }^{\mathrm{b}}$ Determined by DLS.

\section{Effect of surfactant concentration}

Although it is necessary to add a surfactant to stabilize the clay clusters, its concentration should be kept as low as possible. Indeed, low molar mass surfactants can have a detrimental effect on barrier properties by creating preferential tunnels for water vapour molecules in the film material. ${ }^{55}$ A LapS482-DDAB200 (without MPTMS) suspension at $5.2 \mathrm{wt} \%_{\text {toluene }}$ was first emulsified in the presence of $0.7 \mathrm{wt} \%_{\text {toluene }}$ of Dowfax ${ }^{\circledR} 2 \mathrm{~A} 1$ but the organic and aqueous phases remained separated (run M2a, Table 3).

Table 3. Experimental conditions and characteristics of the toluene droplets and clusters for various Dowfax ${ }^{\circledR} 2 \mathrm{~A} 1$ and clay concentrations, Laponite ${ }^{\circledR}$ grades and amounts of intercalated DDAB.

\begin{tabular}{|c|c|c|c|c|c|c|}
\hline \multirow{2}{*}{ Run } & \multirow{2}{*}{ Organoclay } & \multicolumn{3}{|c|}{ Miniemulsion droplets ${ }^{a}$} & \multicolumn{2}{|c|}{$\begin{array}{c}\text { Cluster } \\
\text { suspensions }^{b}\end{array}$} \\
\hline & & $\begin{array}{c}{[\text { Clay] }} \\
\left(\mathrm{wt} \%{ }_{\text {tol }}\right)\end{array}$ & $\begin{array}{l}\text { Dowfax }{ }^{\circledR} \\
\left(\mathrm{wt}_{\mathrm{tol}}\right)^{\mathrm{c}}\end{array}$ & $\begin{array}{c}\mathrm{D}_{\mathrm{h} \text { droplet }} \\
(\mathrm{nm})(\mathrm{PdI})^{\mathrm{d}}\end{array}$ & Run & $\begin{array}{l}\mathrm{D}_{\mathrm{h} \text { cluster }} \\
(\mathrm{nm}) \mathrm{PdI}^{\mathrm{d}}\end{array}$ \\
\hline $\mathrm{M} 2 \mathrm{a}$ & LapS482-DDAB200 & 5.2 & 0.7 & - & - & - \\
\hline $\mathrm{M} 2 \mathrm{~b}$ & LapS482-DDAB200 & 5.2 & 0.9 & $135(0.34)$ & $\mathrm{C} 2$ & $109(0.15)$ \\
\hline M3 & LapS482-DDAB200-MPTMS & 4.9 & 1.0 & $189(0.17)$ & $\mathrm{C} 3$ & $170(0.14)$ \\
\hline M4 & LapS482-DDAB200-MPTMS & 4.9 & 1.0 & $150(0.15)$ & $\mathrm{C} 4$ & $146(0.14)$ \\
\hline M5a & LapS482-DDAB200-MPTMS & 15.9 & 1.7 & - & - & - \\
\hline M5b & LapS482-DDAB200-MPTMS & 15.9 & 3.2 & $174(0.16)$ & C5 & $194(0.25)$ \\
\hline M6 & LapS482-DDAB50-MPTMS & 5.2 & 9.3 & $245(0.43)$ & C6 & $180(0.37)$ \\
\hline M7 & LapS482-DDAB100-MPTMS & 4.9 & 4.2 & $135(0.2)$ & $\mathrm{C} 7$ & $145(0.23)$ \\
\hline
\end{tabular}




\begin{tabular}{ll|lll|ll} 
M8 & LapRD-DDAB100-MPTMS & 4.9 & 3.9 & $256(0.76)$ & C8 & $131(0.24)$ \\
M9 & LapRD-DDAB200-MPTMS & 4.9 & 1.1 & $155(0.23)$ & C9 & $129(0.12)$ \\
\hline
\end{tabular}

${ }^{a} 600 \mathrm{~W}, 5$ minutes by pulses of 20 seconds, Lap-DDAB: $1-3.2 \mathrm{~g}$, MPTMS: 3 mmol g-1 ${ }_{\text {Lap-DDAB }}$, toluene: $20 \mathrm{~g}$; water: 110 - 125 g. ${ }^{b}$ Cluster suspensions obtained after toluene evaporation by rotary evaporator. ${ }^{\mathrm{c}}$ Active weight of Dowfax ${ }^{\circledR} 2 \mathrm{~A} 1 .{ }^{\mathrm{d}}$ Determined by DLS.

Consequently, the Dowfax ${ }^{\circledR}$ 2A1 concentration was progressively increased to determine the minimum amount required to emulsify the mixture. Stable droplets with a small diameter (135 $\mathrm{nm}$ ) were obtained for $0.9 \mathrm{wt} \%$ toluene of Dowfax (run M2b), system obtained under conditions that are similar to those reported above for M1f (Table 2). The same study carried out with LapS482-DDAB200-MPTMS led to a similar value (1.0 $\mathrm{wt} \%_{\text {toluene, }}$ run M3) although the droplet size was slightly higher. Lastly, we used a more concentrated clay suspension (15.9 $\left.\mathrm{wt} \%_{\text {toluene }}\right)$ and the minimal surfactant concentration required to form a stable emulsion increased to $3.2 \mathrm{wt} \%_{\text {toluene }}$ while in parallel the droplet size increased to $174 \mathrm{~nm}(\mathrm{PdI}=0.16)$ (runs M3 and M5b), which is likely related to the increase of the viscosity of the oil phase with increasing clay content. ${ }^{56}$

This first series of experiments seem thus to indicate that a minimal concentration of Dowfax ${ }^{\circledR} 2 \mathrm{~A} 1$ is required to obtain stable miniemulsions and that this minimal amount increases with increasing clay content. Considering that the main role of the surfactant is to stabilize the droplets by adsorbing at the oil/water interface and that the toluene weight fraction was kept constant (around $15 \mathrm{wt} \%$ ), we did not expect the Dowfax concentration to be such a critical parameter. A possible explanation is that an electrostatic attraction occurred at the droplet interface between the two oppositely charged surfactants, namely the cationic DDAB in excess (with respect to the CEC) and the anionic Dowfax ${ }^{\circledR} 2 \mathrm{~A} 1$ molecules. To test this hypothesis, another series of experiments was thus carried out by varying the amount of DDAB. 


\section{Effect of the amount of DDAB}

In this section, the amount of intercalated DDAB was varied targeting 50, 100 and $200 \%$ of CEC while the clay content was fixed at $5 \mathrm{wt} \%_{\text {toluene }}$ (runs M6 to M9, Table 3). It clearly appears that the quantity of Dowfax ${ }^{\circledR} 2 \mathrm{~A} 1$ required for successful emulsification gradually increased as the quantity of DDAB intercalated in the clay galleries decreased. For example, LapS482-DDAB50-MPTMS (run M6) required ten times more Dowfax ${ }^{\circledR}$ 2A1 than LapS482DDAB200-MPTMS (run M4) to form a stable emulsion, and also led to larger droplets (245 $\mathrm{nm}$ for $50 \%$ CEC (run M6, PdI = 0.43) vs $150 \mathrm{~nm}$ for 200\% CEC (run M4, PdI = 0.15). Similar results were obtained for Laponite ${ }^{\circledR} \mathrm{RD}$ : more anionic surfactant was required for the miniemulsion containing the less DDAB, indicating that the two Laponite grades behaved the same way (runs M8 and M9, Table 3). These results thus clearly show that the amount of intercalated DDAB plays a crucial role on droplet size and stability. Interestingly, calculation of the ratio between the number of sulfonate groups from Dowfax ${ }^{\circledR} 2 \mathrm{~A} 1$ and the number of ammonium groups from the DDAB in excess (considering that one Dowfax molecule contains two sulfonate groups and one DDAB molecule contains only one ammonium head), shows that unstable miniemulsions were obtained for charge ratios lower than one, which conditions correspond to catanionic complex formation with excess cationic surfactant (see Table S3 in the Supporting Information). This result and the fact that it is necessary to increase the Dowfax concentration to get a stable miniemulsion for DDAB contents below the CEC, suggest that the catanionic complex formed by electrostatic interactions between the DDAB in excess and Dowfax 2A1 is more effective in stabilizing the oil/water interface than the anionic or cationic surfactants alone (see Scheme S2 in the Supporting Information). Control experiments performed in the absence of clay under otherwise the same experimental conditions, further confirmed this assumption (runs M10 to M13 in Table S4, Supporting Information). Indeed, while DDAB was not capable to stabilize the emulsion, only a moderate 
stability was obtained in the presence of Dowfax® ${ }^{\circledR} \mathrm{A} 1$. In contrast, stable miniemulsion droplets were obtained in the presence of both surfactants with molar excess of Dowfax® 2A1. Furthermore, another parameter to be taken into account is the intrinsic hydrophobicity of the clay platelets. For DDAB contents below the CEC, the inorganic platelets keep a hydrophilic character and their dispersion in toluene is not optimal, which may also affect the emulsification process, whilst on the other hand excess of DDAB can facilitate the swelling of the platelets in nonpolar solvents thanks to its two long alkyl chains releasing DDAB molecules from the interlayer space, which would promote catanionic complex formation at the oil/water interface. To go one step further, the miniemulsion droplets containing the double functionalized Laponite clay intercalated at 100\% the CEC (run M7, Table 3) were observed by cryo-TEM (Figure 2A).
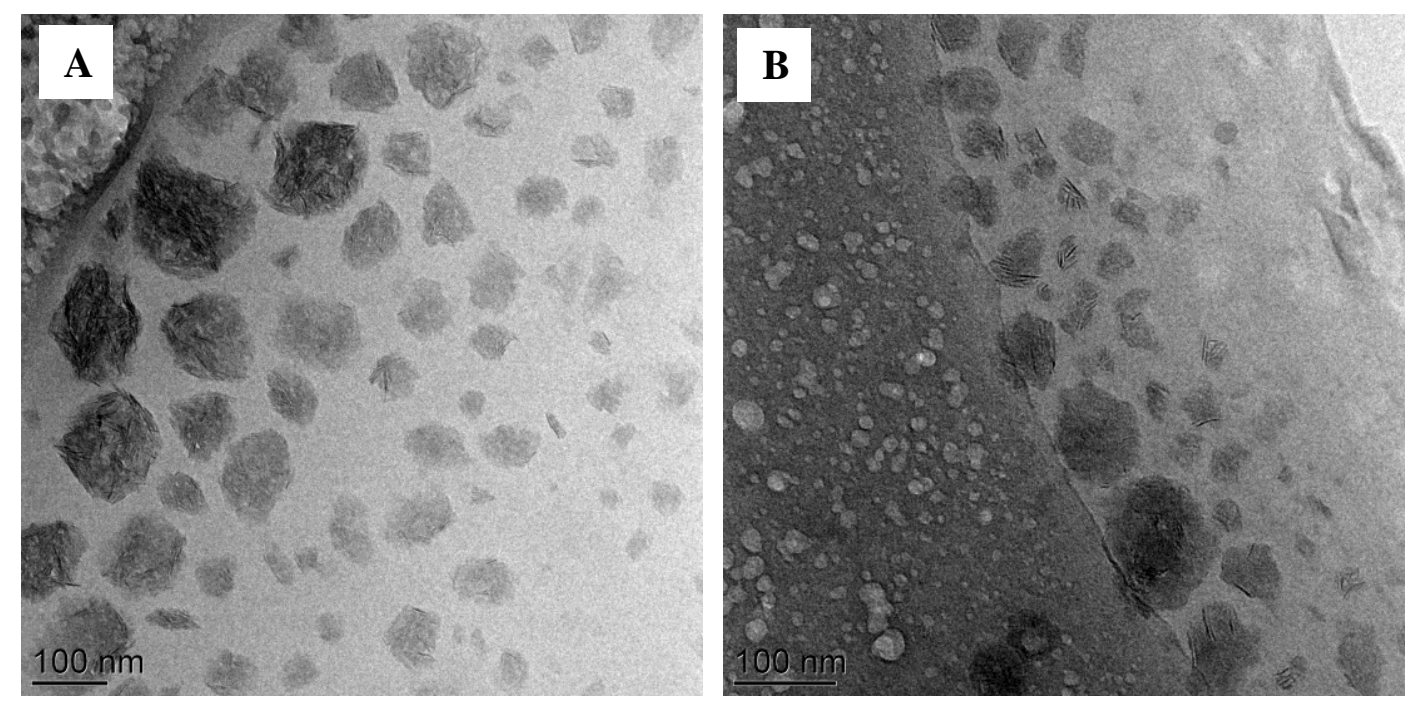

Figure 2. Cryo-TEM images of: A) LapS482-DDAB100-MPTMS/toluene droplets stabilized by Dowfax ${ }^{\circledR} 2 \mathrm{~A} 1$ (run M7, Table 3) and B) the resulting cluster suspension obtained after removal of toluene by evaporation (run C7, Table 3) (scale bar: $100 \mathrm{~nm}$ ).

Although this technique allows imaging soft and/or deformable materials, toluene presents a low contrast and it was not possible to distinguish the contours of the droplets, the observed objects displaying a distorted non-spherical shape. As evidenced by the image, the clay sheets 
are organized as small stacks of a few platelets (from now on referred to as tactoids) aggregated together into the droplets. It has been demonstrated elsewhere that Laponite clays treated with dialkyl chain cationic surfactants (namely, dimethyl dioctadecylammonium bromide) do not fully exfoliate in toluene. ${ }^{51}$ It was shown that the solvent swells the clay sheets resulting in intercalated stacks in agreement with the present observation. Besides, clay modification with the MPTMS trifunctional silane may have further crosslinked the clay platelets together through their edges, ${ }^{57}$ preventing the clay stacks from expanding in the droplets and potentially migrating to the oil/water interface, accounting for the observed irregular shape and aggregated morphology. In addition, as seen in Figure 2A, the large droplet size distribution inevitably led to variations in the number of platelets per droplet, and both big objects (around $120 \mathrm{~nm}$ in diameter) containing a lot of platelets as well as smaller objects $(\approx 30 \mathrm{~nm})$ containing only a few platelets could be observed.

\section{Formation of clay clusters}

Ideally, toluene evaporation should confine the clay platelets into clusters stabilized by the surfactant molecules (Dowfax ${ }^{\circledR} 2 \mathrm{~A} 1$ and DDAB). Table 3 shows the characteristics of all the clusters obtained from the miniemulsions discussed above. It is first noticeable that the PdI values determined after solvent evaporation remained broad, so the sizes obtained by DLS should not be given too much weight and should only be taken as indicative of the general trend. The miniemulsion M2 presents a size of $135 \mathrm{~nm}(\mathrm{PdI}=0.34)$ and the cluster suspension shows a slight contraction with a diameter of $109 \mathrm{~nm}(\mathrm{PdI}=0.15)$. In fact, most of the cluster suspensions exhibited smaller diameters as well as smaller PdI values than the original miniemulsions, although for some samples there was no difference (runs C3, C4) and for others the diameter slightly increased (run C7). It is most likely that emulsion droplets devoid of clay were formed concomitantly to clay-loaded droplets, resulting in organoclay being 
dispersed in only a fraction of the toluene, leading therefore to minor variations of particles size when compared to the droplet size. In fine, for all Lap $x$-DDAB $y$-MPTMS, we observed a particle size between 129 and $194 \mathrm{~nm}$ with a PdI value comprised between 0.12 and 0.37 . As can be observed in the cryo-TEM image of Figure 2B (run C7, Table 3), the clusters are made of tactoids of 3-5 individual clay sheets stacked on top of each other with a gap of a few nanometers in between each. The tactoids are disposed in a random orientation within the clusters and are more clearly visible when they are oriented edge-on. This gives the resulting clay assembly an irregular, distorted shape and there is no significant difference between those images and the previous ones from the miniemulsion, providing further evidence that the organosilane linked the clay sheets together and fixed the morphology.

To conclude, the developed strategy has enabled the preparation of aqueous suspensions of clay platelets stacked together into clusters from organomodified Laponite platelets previously dispersed into toluene droplets. The key parameters influencing droplet formation are the fraction of toluene in the toluene/water mixture and the hydrophobicity of the organoclay, which in turn depends on the quantity of intercalated DDAB. Indeed, a lower amount of anionic surfactant was required to stabilize the droplets for the hydrophobic clays (i.e., those exchanged at $200 \%$ CEC) than for the hydrophilic ones. The miniemulsion and cluster suspensions were stable for at least 6 months with no variation of droplet and particle size (data not shown). It was thus possible to store them before use. The next section will describe the synthesis of latexes using these clusters as seeds in emulsion polymerization.

\section{Synthesis of $\mathrm{P}(\mathrm{Sty}-\mathrm{co}-\mathrm{MA}) /$ Laponite ${ }^{\circledR}$ composite latexes}

In a preliminary study, we investigated the encapsulation of the clusters into $\mathrm{P}(\mathrm{Sty}-\mathrm{co}-\mathrm{MA})$ latex particles. Styrene was considered in the first place for two reasons: i) samples could be easily taken out from the reactor to perform kinetic analyses, and ii) the particle morphology 
could be conveniently observed by TEM. Besides, Sty and VDC both have low water solubilities $\left(0.3 \mathrm{~g} \mathrm{~L}^{-1}\right.$ and $2.5 \mathrm{~g} \mathrm{~L}^{-1}$ at $25^{\circ} \mathrm{C}$, respectively) when compared to MA $\left(60 \mathrm{~g} \mathrm{~L}^{-1}\right)$ and styrene was thus considered to be a relevant model monomer. The Sty/MA weight ratio was fixed at 90/10 in order to compare with further experiments based on VDC. Two comparative experiments were first performed (namely, P2 and P3) to evaluate the effect of the silane on encapsulation using a cluster suspension without or with MPTMS (C2 and C3, respectively). The organoclay content was fixed at $5 \mathrm{wt} \%$ based on monomers. Figure 3 shows the evolution of the particle size and of the particle number with conversion for these two experiments. The first kinetic study was performed in the presence of LapS482DDAB200 targeting $17 \%$ solids content $(\tau)$ (run P2, Figure $3 \mathrm{~A}$ ). The conversion reached $86 \%$ in 3 hours while the particle size decreased from $109 \mathrm{~nm}$ before polymerization $(\mathrm{PdI}=$ $0.15)$ to around $80 \mathrm{~nm}(\mathrm{PdI}=0.04)$ at $9 \%$ conversion. The particle diameter then steadily increased to $158 \mathrm{~nm}$ while the final PdI value remained quite low (0.03). TEM analysis shows that the tactoid morphology has completely disappeared, the clay platelets being preferentially located at the polymer/water interface. Some particles have platelets on their surface while others are devoid of clay. As there was no silane involved in this experiment, we hypothesized that the styrene swelled the clusters in the early stages of the polymerization, significantly decreasing the internal viscosity of the seed particles, allowing the clay platelets to migrate to the particle/water interface in a thermodynamic process. Such a morphology also hints at a poor compatibility between the polymer matrix and the organoclay as previously reported in the literature for cerium dioxide encapsulation by miniemulsion polymerization. ${ }^{58}$ In the meantime, the use of a relatively high Dowfax concentration (i.e., $1.5 \mathrm{~g} \mathrm{~L}^{-1}$ ), well above its critical micelle concentration $\left(0.07 \mathrm{~g} \mathrm{~L}^{-1}\right)$, may have favored secondary nucleation. This assumption is supported by the rapidly increasing and high number of particles (Figure 3A), as well as by the observation of platelet-free particles on the TEM images. 
A

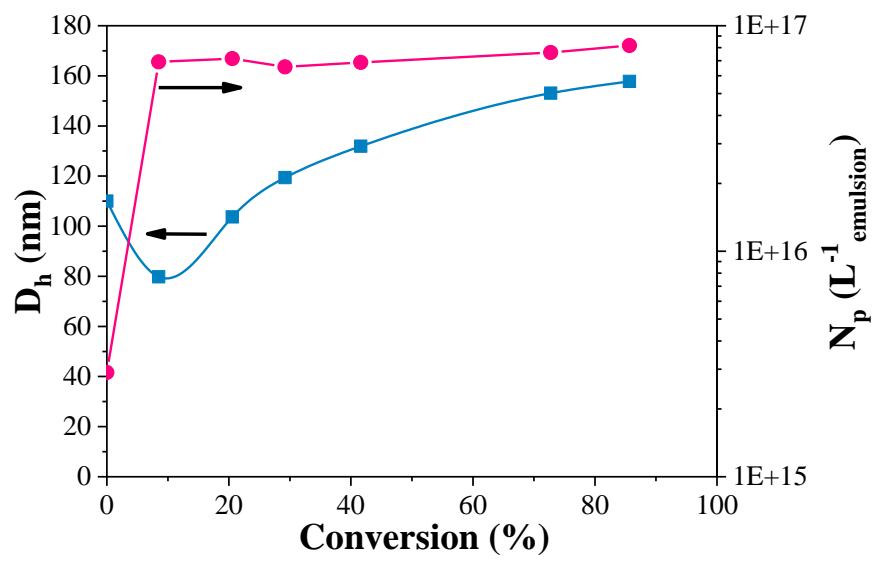

C

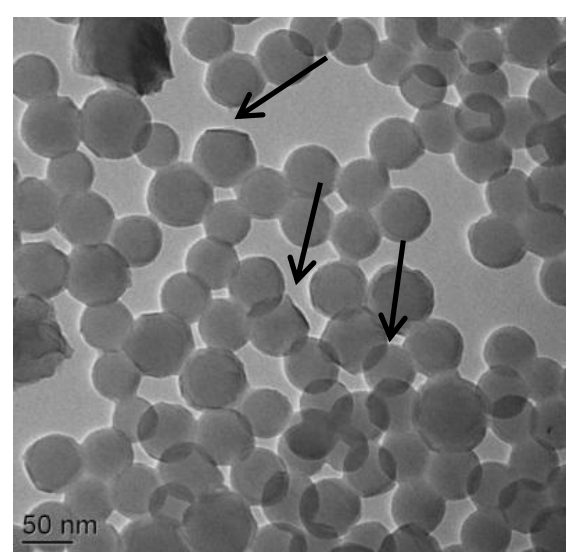

$\mathrm{t}=15 \min , \mathrm{X}=8.5 \%$

$\tau_{\text {exp }}=1.4 \%, \mathrm{D}_{\mathrm{h}}=80 \mathrm{~nm}$

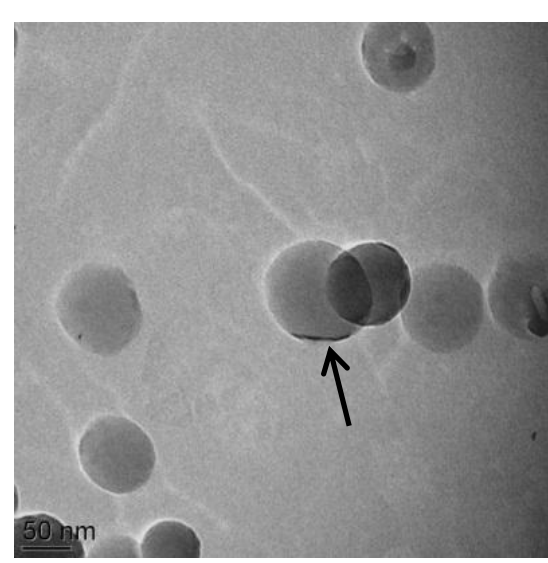

$\mathrm{t}=30 \mathrm{~min}, \mathrm{X}=21 \%$, $\tau_{\text {exp }}=3.5 \%, \mathrm{D}_{\mathrm{h}}=104 \mathrm{~nm}$
B

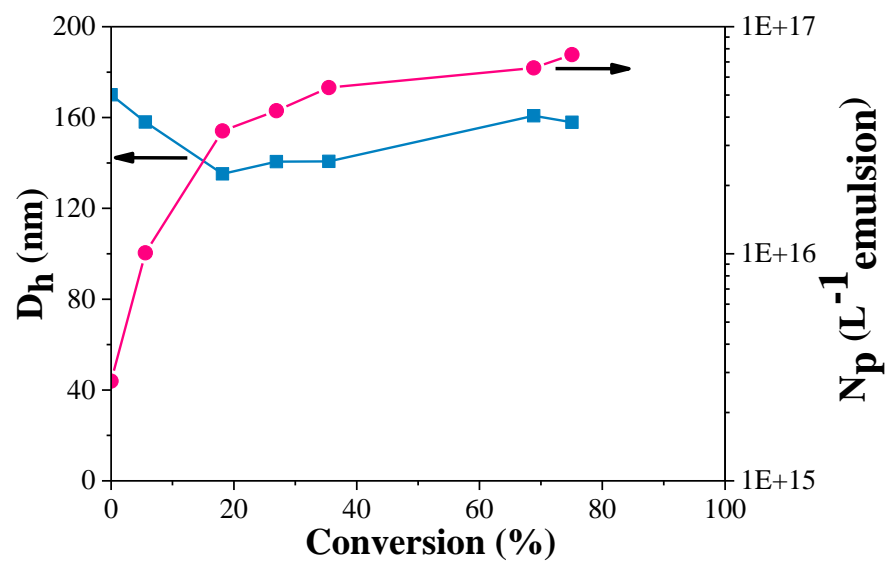

D

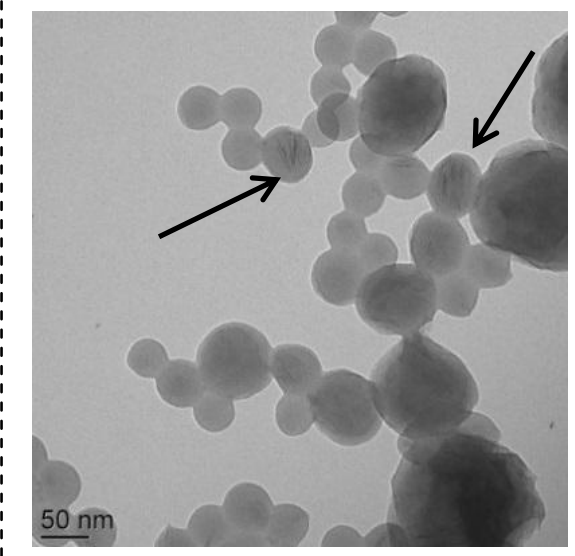

$\mathrm{t}=15 \mathrm{~min}, \mathrm{X}=5.6 \%$

$\tau_{\text {exp }}=0.9 \%, D_{\mathrm{h}}=158 \mathrm{~nm}$

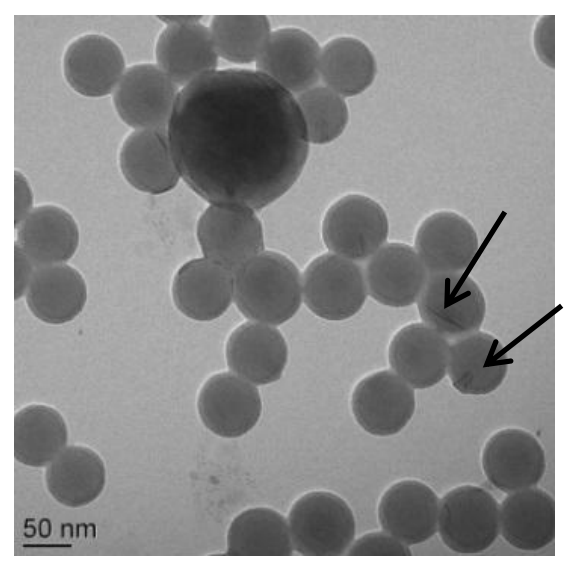

$\mathrm{t}=30 \mathrm{~min}, \mathrm{X}=18 \%$

$\tau_{\exp }=3.1 \%, D_{h}=135 \mathrm{~nm}$

Figure 3. A-B. Particle diameter and particle number (logarithm scale) vs conversion for $\mathrm{P}(\mathrm{Sty}-c o-\mathrm{MA}) / \mathrm{LapS} 482-\mathrm{DDAB} 200$ (run $\mathrm{P} 2$ ) and $\mathrm{P}(\mathrm{Sty}-$ co-MA)/LapS482-DDAB200-MPTMS (run P3) composite latexes, respectively. C-D. TEM images of the P(Sty-co-MA)/LapS482-DDAB200 and $\mathrm{P}(\mathrm{Sty}-\mathrm{co}$-MA)/LapS482-DDAB200-MPTMS composite latexes after 15 and $30 \mathrm{~min}$ of reaction, respectively. The arrows point to some Laponite ${ }^{\circledR}$ platelets. TO BE DISPLAYED OVER TWO COLUMNS 
Indeed, a substantial amount of Dowfax ${ }^{\circledR} 2 \mathrm{~A} 1$ may be present in water at the beginning of the polymerization. Although the amount of Dowfax used for miniemulsification was minimized, some surfactant molecules can be released in water during solvent evaporation from either the clay-loaded (due to volume contraction) or the initial platelet-free toluene droplets.

The same experiment was then performed with LapS482-DDAB200-MPTMS (run P3, Figure 3B). The original clusters $(\mathrm{C} 3)$ had a diameter of $170 \mathrm{~nm}(\mathrm{PdI}=0.14)$. The particle size first decreased to around $140 \mathrm{~nm}$ at $40 \%$ conversion and then increased to $158 \mathrm{~nm}(\mathrm{PdI}=0.3)$ after 3 hours of reaction, which corresponds to $75 \%$ conversion. The number of particles steadily increased to $7.510^{16} \mathrm{~L}^{-1}$ emulsion, which is one order of magnitude higher than the number of clusters (estimated to be about $310^{15} \mathrm{~L}^{-1}$ ), suggesting again secondary nucleation. The steady increase in particle number with conversion compared to the constant value observed in the case of P2, indicates that the silane influenced the nucleation stage. Prolonged nucleation may be due in this case to the lower seed number resulting in a higher amount of free surfactant available to stabilize newly formed particles, together with the crosslinking structure of the clay cluster that may limit their swelling by the monomer and thus favour the competitive growth of the new particles. As above in the absence of silane, TEM indeed confirmed the formation of free latex particles since the early stage of the polymerization. Clay tactoids located inside or near the particles' surface could also be clearly seen. As demonstrated by Negrete-Herrera, ${ }^{57}$ trifunctional silane coupling agents allow the covalent bonding of individual platelets into irreversibly attached clay stacks thanks to hydrolysis/condensation reactions. In our system, the organosilane is actually key in controlling particle morphology. Indeed, edge functionalization links the clay sheets together but also covalently binds the platelets to the polymer matrix. This enables the cluster integrity to be maintained during the swelling step and also prevents migration of the platelets to the polymer/water interface during polymerization. In our opinion, the obtained latex results from 
a combination of a seeded cluster nucleation and, to a certain extent, of secondary nucleation, leading to a mixture of composite $\mathrm{P}(\mathrm{Sty}-\mathrm{co}-\mathrm{MA}) / \mathrm{clay}$ particles together with pure polymer particles.

As illustrated in Figure 3C and 3D, the clay platelets are easily observed by TEM at low conversion, which was not the case in the final sample, i.e. for conversions close to $80 \%$. Hence, the morphology of the final $\mathrm{P}(\mathrm{Sty}-\mathrm{co}-\mathrm{MA}) /$ clay particles was characterized by highangle annular dark-field-scanning transmission electron microscopy (HAADF-STEM) (Figure 4). With this technique, the heaviest elements appear lighter. The bright areas thus correspond to the Laponite ${ }^{\circledR}$ platelets, whereas darker areas correspond to the polymer. The electronic image of Figure 4a shows numerous white areas indicating that the Laponite ${ }^{\circledR}$ platelets are located inside the particles. Indeed, if the platelets were located on the particle surface, a white crown would be visible as previously observed for clay-armored latexes. ${ }^{59}$ The mapping also reveals that carbon, oxygen, silicon and magnesium are uniformly distributed inside the particles providing clear and unambiguous evidence of clay encapsulation (Figure $4 b, c, d$ and e, respectively). Since the beam passes through the particles, this shows that a sufficient quantity of those elements is present in the core to be detected. For the sake of completeness, the same analysis was performed on the latex synthesized in the absence of silane (run P2). The HAADF-STEM images of Figure S5 (Supporting Information) clearly show the presence of silicon and magnesium at the particles surface supporting the above conclusion that the clay is mainly located at the polymer/water interface in this case. 


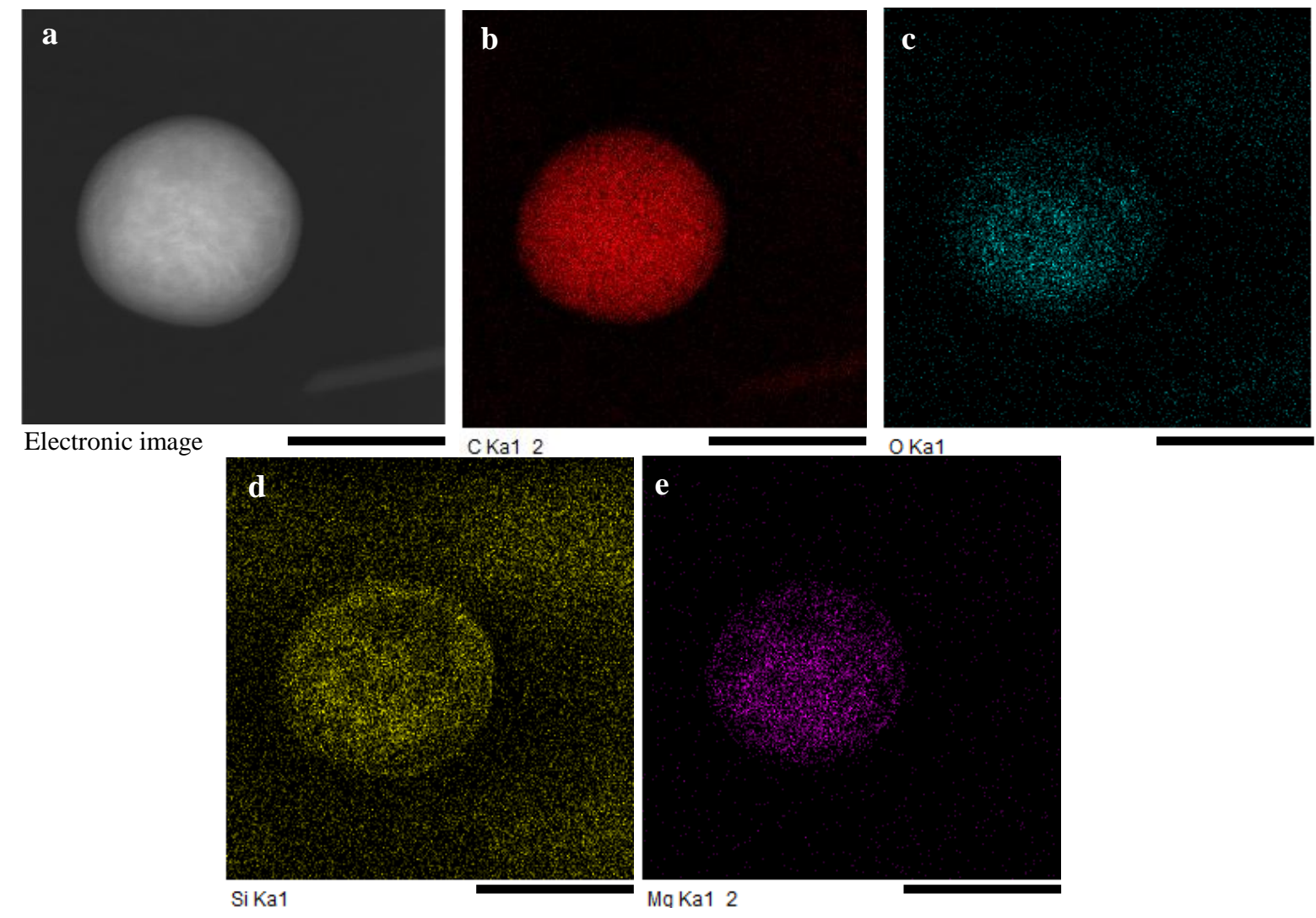

Figure 4: HAADF-STEM images of $\mathrm{P}(\mathrm{Sty}-\mathrm{co}-\mathrm{MA}) / \mathrm{LapS482-DDAB200-MPTMS} \mathrm{composite}$ particles (run P3). a) Electronic image and mapping of b) carbon, c) oxygen, d) silicon and e) magnesium (scale bar: $200 \mathrm{~nm}$ ).

To conclude, this preliminary study conducted with styrene as a model monomer has highlighted the crucial role of MPTMS to successfully encapsulate Laponite clay platelets into polymer latex particles. The trifunctional silane formed crosslinked structures around the clay sheets and also promoted covalent grafting to the polymer chains, which enabled to preserve the integrity of the clusters, preventing migration of the clay platelets to the polymer/water interface during the emulsion polymerization reaction. Transposition of this approach to the synthesis of VDC-based composite latexes will be explored in the next section.

\section{Synthesis of P(VDC-co-MA)/Laponite® composite latexes}


The possibility of implementing our encapsulation strategy for a new monomer combination (i.e. VDC/MA - 90/10 wt\%) was first investigated with LapS482-DDAB200-MPTMS. The obtained clay clusters (C4, Table 3) had a diameter of $146 \mathrm{~nm}$ and a PdI value of 0.14 . The synthesized latex (run P4, Table 4) was stable and the final particles size was $145 \mathrm{~nm}$ with a low PdI value (0.02). Full conversion was reached in less than 90 minutes and the final $\mathrm{pH}$ was 2.8. It is worth mentioning that usually gelation of bare Laponite suspensions occurs at low $\mathrm{pH}^{60}$ In a recent contribution, we have reported the synthesis of Laponite-armoured P(VDC-co-MA) latex particles. ${ }^{59}$ In this previous work, the clay platelets were initially dispersed in water and located at the particle surface at the end of the polymerization, leading to a neutral final $\mathrm{pH}$. In the present strategy, the same system (identical VDC/MA ratio, initiator and no buffer) led to an acidic $\mathrm{pH}$, characteristic of PVDC latexes. This low $\mathrm{pH}$ value is actually a first evidence of an efficient clay encapsulation. The absence of gelation in such low $\mathrm{pH}$ value conditions, further indicates that the clay platelets are not located in the water phase or at the particle's surface but effectively encapsulated into the PDVC particles. The latex morphology was further characterized by HR-TEM, which confirmed the presence of Laponite clay sheets inside the P(VDC-co-MA) particles (Figure 5A). The platelets do not appear as exfoliated individual clay sheets, but are instead organized as stacks of a few layers remindful of the original cluster morphology. The tactoids are surrounded by polymer and homogeneously distributed within the particles. Some platelets also seem to be located on or near the particles' surface. However, as the polymer matrix had a low glass transition temperature $\left(\mathrm{T}_{\mathrm{g}}=15^{\circ} \mathrm{C}\right),{ }^{59}$ it had a tendency to flow under the electron beam, and we therefore carried out additional cryo-TEM analyses in order to prevent any misinterpretation (Figure 5B). The contrast was not as good as in HR-TEM but we could clearly distinguish in some of the particles, the presence of embedded clay tactoids. A closer look at the image 
indicates that the polymer has grown outward from the clay clusters that are surrounded by a thin polymer shell.

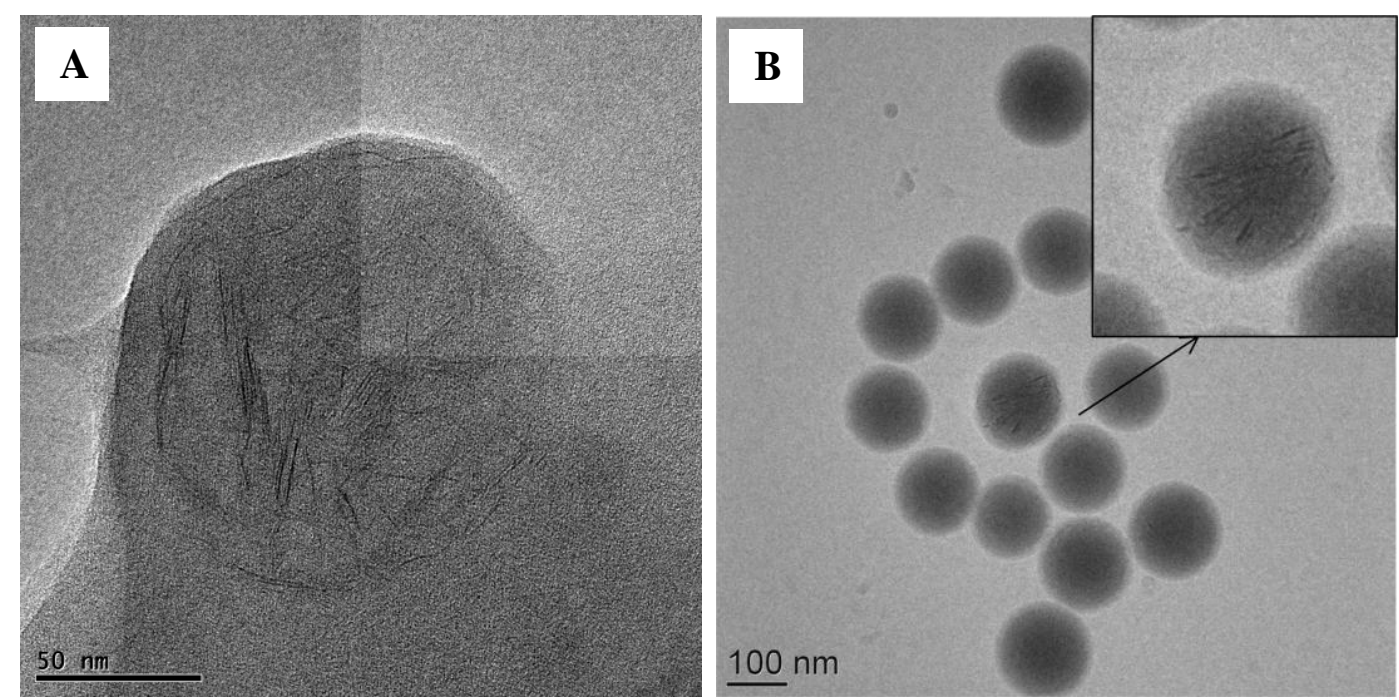

Figure 5. A. HR-TEM and B. Cryo-TEM images of P(VDC-co-MA) particles synthesized by seeded emulsion polymerization using the LapS482-DDAB200-MPTMS cluster suspension as seed $(\mathrm{VDC} / \mathrm{MA}=90 / 10 \mathrm{wt} / \mathrm{wt}$ and $\tau=18 \mathrm{wt} \%$ ). See Table 4 (run P4) for detailed experimental conditions.

Following successful incorporation of the LapS482-DDAB200-MPTMS organoclay into PVDC/MA particles, we extended our investigations to include organoclays with various degrees of hydrophobicity by employing the three types of clusters obtained from Laponite S482 and modified by different amounts of DDAB (C6, C7 and C4, in Table 3). In all cases, stable latexes (respectively runs P6, P7 and P4, Table 4) were obtained. Particle diameters gradually decreased as the organomodified clay became less hydrophobic $(102 \mathrm{~nm}$ and $77 \mathrm{~nm}$ for LapS482-DDAB100-MPTMS and LapS482-DDAB50-MPTMS, runs P7 and P6, respectively) but the PdI values were quite high (>0.10) compared to LapS482-DDAB200MPTMS (run P4, PdI = 0.02). These cluster suspensions contained a higher amount of Dowfax ${ }^{\circledR} 2 \mathrm{~A} 1$ - due to their lower DDAB content, as explained previously -, and this likely promoted secondary nucleation as attested by the decrease in particle diameter. Similar results 
were obtained for Laponite RD: the lower the DDAB content, the higher the amount of Dowfax ${ }^{\circledR} 2 \mathrm{~A} 1$, and the smaller was consequently the particle diameter (runs P9 and P8 in Table 4). Even if the platelets were effectively encapsulated in the particle core (Figure S6, Supporting Information), the high surfactant concentrations $\left(\geq 8.5 \mathrm{~g} \mathrm{~L}_{\mathrm{water}}{ }^{-1}\right)$ used in these experiments can negatively impact the water vapour barrier properties of the final material by increasing permeability, and clays with low DDAB contents (50 and 100\% CEC) should be therefore avoided for the purpose of this work. It is worth noting that all the latexes were stable over a year and did not show any significant change in $\mathrm{pH}$ (Figure S7, Supporting Information).

\section{Formation of P(VDC-co-MA)/Laponite ${ }^{\circledR}$ nanocomposite films}

In this last part, we studied the morphology of the films obtained from the P(VDC-coMA)/Laponite latexes. The thin films obtained were all white and as flexible as their clay-free homologues (data not shown), which contrasts with our previous work on the synthesis of clay-armoured PVDC particles, where we obtained brittle films due to the formation of a honeycomb structure. ${ }^{59}$ The nanostructure of the film formed from the P(VDC-coMA)/LapS482-DDAB200-MPTMS composite latex (run P4, Table 4) was further examined by preparing thin cross-sectional slices. As shown in Figure 6, the film displays spherical domains of clay tactoids homogenously dispersed in the matrix. The clay inclusions are composed of stacks of a few platelets disposed in random orientation with respect to each other. We also note that the composition and the size of the inclusions are heterogeneous. Some inclusions contain a lot of clay tactoids whereas others contain only a few platelets, which is consistent with the initial cluster size distribution. The clay-rich domains thus likely correspond to the core of the composite latex particles indicating that the latter have undergone coalescence with secondary nucleated latex particles to form a homogeneous film. 
Table 4. Experimental conditions and characteristics of the final latexes obtained by emulsion copolymerization of

VDC and MA in the presence of various cluster suspensions. ${ }^{a}$

\begin{tabular}{lccccccc}
\hline Run & $\begin{array}{c}\text { Organoclay } \\
\text { (Cluster batch) }\end{array}$ & $\begin{array}{c}\text { Dowfax }{ }^{\circledR} \text { 2A1 } \\
\left(\mathrm{g} \mathrm{L}_{\text {water }}^{-1}\right)\end{array}$ & $\begin{array}{c}\mathrm{X}^{\mathrm{b}} \\
(\%)\end{array}$ & $\begin{array}{c}\tau_{\text {exp }}{ }^{\mathrm{c}} \\
(\%)\end{array}$ & $\begin{array}{c}\mathrm{D}_{\mathrm{h}} \text { clusters } \\
(\mathrm{PdI})^{\mathrm{d}}\end{array}$ & $\begin{array}{c}\mathrm{D}_{\mathrm{h}} \text { particles } \\
(\mathrm{PdI})^{\mathrm{d}}\end{array}$ & $\mathrm{pH}_{\mathrm{f}}$ \\
\hline P6 & LapS482-DDAB50-MPTMS (C6) & 18.4 & 100 & 18 & $180(0.37)$ & $77(0.19)$ & 4.3 \\
P7 & LapS482-DDAB100-MPTMS (C7) & 8.5 & 94 & 17 & $145(0.23)$ & $102(0.10)$ & 4.0 \\
P4 & LapS482-DDAB200-MPTMS (C4) & 2.0 & 100 & 18 & $146(0.14)$ & $145(0.02)$ & 2.8 \\
\hline P8 & LapRD-DDAB100-MPTMS (C8) & 7.8 & 100 & 18 & $131(0.24)$ & $85(0.13)$ & 2.3 \\
P9 & LapRD-DDAB200-MPTMS (C9) & 2.1 & 95 & 17 & $129(0.12)$ & $175(0.03)$ & 2.6 \\
\hline
\end{tabular}

${ }^{\mathrm{a}}$ All polymerizations were performed at $70{ }^{\circ} \mathrm{C}$ and $300 \mathrm{rpm}$ with water: $100 \mathrm{~g}$, VDC/MA: $90 / 10 \mathrm{wt} \%$, $\tau_{\text {theo }}: 17 \mathrm{wt} \%$, APS: $0.5 \mathrm{wt} \%$ based on monomers (bom), Lapx-DDABy:-MPTMS $4 \mathrm{wt} \%$ bom, MPTMS: $4 \mathrm{mmol} \mathrm{g}^{-1}$ Laponite. ${ }^{\mathrm{b}}$ Conversion determined by gravimetric analysis. ${ }^{\mathrm{c}}$ Overall solids content. ${ }^{\mathrm{d}}$ Determined by DLS (the curves are available in SI, Figure S8). 
The presence of free latex particles and of a thin polymer shell around the clay clusters may have facilitated polymer chain interdiffusion across particle boundaries, which is key in obtaining a cohesive film.
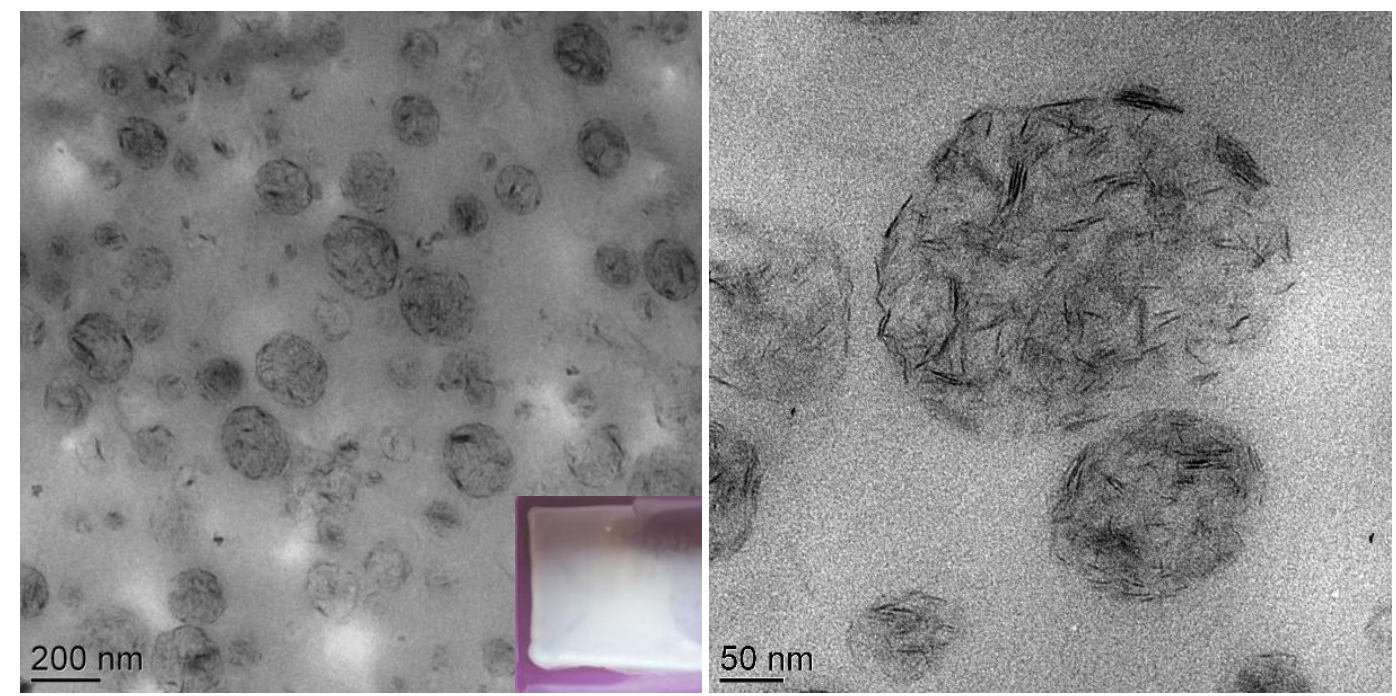

Figure 6. TEM images of an ultrathin cross-section of the P(VDC-co-MA)/LapS482DDAB200-MPTMS composite film (run P4, Table 4). Insert: digital photo of the macroscopic film.

\section{CONCLUSIONS}

Through the formation of clusters containing hydrophobic Laponite® platelets, composite polymer/clay particles were successfully obtained via seeded emulsion polymerization. Hydrophobization of the Laponite ${ }^{\circledR}$ platelets was undertaken to ensure a good compatibility of the clay sheets with toluene first, and then with the polymer. Various amounts of the cationic DDAB surfactant were incorporated into the platelet's interlayer through cation exchange, while the clay edges were modified with a methacrylate-terminated trialkoxysilane (MPTMS). The organomodified platelets were dispersed in toluene and ultrasonicated with an aqueous solution of Dowfax® $2 \mathrm{~A} 1$ to form stable clay-loaded droplets. The quantity of 
Dowfax ${ }^{\circledR} 2 \mathrm{~A} 1$ required for the emulsification gradually increased as the quantity of DDAB intercalated in the clay decreased, suggesting that the catanionic complex structures formed between the DDAB in excess and Dowfax ${ }^{\circledR} 2 \mathrm{~A} 1$ were more effective in stabilizing the interface than the anionic or cationic surfactants alone. Toluene evaporation led to the formation of Laponite ${ }^{\circledR}$ clusters, which were subsequently used as seeds in the emulsion polymerization of first Sty/MA, and then VDC/MA. In both cases, stable and spherical colloidal nanoparticles, around $150 \mathrm{~nm}$ in diameter, were obtained in a fast, robust and reproducible process. The organosilane was key in controlling particle morphology, enabling to maintain the integrity of the clay cluster during the swelling step and also preventing migration of the platelets to the polymer/water interface during polymerization, leading to successful encapsulation. TEM analysis of the composite latexes indeed revealed the formation of encapsulated clay sheets composed of stacks of a few platelets embedded in the particle core. Some polymer latex particles devoid of clay platelets were also produced by secondary nucleation. Analysis of the nanocomposite film obtained from the PVDC/Laponite ${ }^{\circledR}$ latex showed that the clay tactoids were confined into spherical inclusions dispersed within the polymer matrix. The innovative strategy developed in this study for clay encapsulation avoids the critical sonication step for sensitive monomers like VDC. The limitless variations of the monomer nature and composition offer great potential to this clay cluster-seeded emulsion polymerization process that can be potentially extended to other fields of applications and/or other inorganic materials.

\section{ASSOCIATED CONTENT}

\section{Supporting Information}

The Supporting Information is available free of charge on the ACS Publications website at DOI: 
Analyses of organomodified Laponite ${ }^{\circledR}$ by FTIR, WAXS and TGA. Control miniemulsion experiments in the absence of clay, additional HAADF STEM and cryo-TEM images, longterm stability of the composite latex suspensions and DLS data.

\section{ACKNOWLEDGMENT}

The authors thank BYK additives for kindly providing Laponite ${ }^{\circledR}$ samples. The CT $\mu$ is greatly acknowledged for its help during HAADF-STEM observations. The authors are also grateful to Fabrice Brunel for its help and guidance during WAXS analyses.

\section{REFERENCES AND NOTES}

1. Mittal, V., Barrier properties of composite materials. In Barrier Properties of Polymer Clay Nanocomposites, Mittal, V., Ed. Nova Science Publishers: New York, 2009.

2. Al-Qadhi, M.; Merah, N.; Gasem, Z. M. Mechanical properties and water uptake of epoxy/clay nanocomposites containing different clay loadings. J. Mater. Sci. 2013, 48, 3798-3804.

3. Ollier, R.; Rodriguez, E.; Alvarez, V. Unsaturated polyester/bentonite nanocomposites: Influence of clay modification on final performance. Compos. Part A. Appl. Sci. Manuf. 2013, 48, 137-143.

4. Cheng, H.-Y.; Jang, G.-W. W. Enhanced thermal Properties and Gas Barrier Property of PMMA Nanocomposites with Layered Silicate via Soap-Free Emulsion Polymerization. Mater. Res. Soc. Symp. Proc. 2007, 951.

5. Yilmaz, O. A hybrid polyacrylate/OMMT nanocomposite latex: Synthesis, characterization and its application as a coating binder. Prog. Org. Coat. 2014, 77, 110-117.

6. LeBaron, P. C.; Wang, Z.; Pinnavaia, T. J. Polymer-layered silicate nanocomposites: an overview. Appl. Clay Sci. 1999, 15, 11-29.

7. Lu, C.; Mai, Y.-W. Influence of Aspect Ratio on Barrier Properties of Polymer-Clay Nanocomposites. Phys. Rev. Lett. 2005, 95, 088303.

8. Lu, C.; Mai, Y.-W. Permeability modelling of polymer-layered silicate nanocomposites. Compos. Sci. Technol. 2007, 67, 2895-2902.

9. Gain, O.; Espuche, E.; Pollet, E.; Alexandre, M.; Dubois, P. Gas barrier properties of poly $(\varepsilon-$ caprolactone)/clay nanocomposites: Influence of the morphology and polymer/clay interactions. $J$. Polym. Sci. Part B: Polym. Phys. 2005, 43, 205-214.

10. Zhu, Y. D.; Allen, G. C.; Adams, J. M.; Gittins, D. I.; Hooper, J. J.; Skuse, D. R. Barrier properties of latex/kaolin coatings. Polym. Chem. 2013, 4, 4386-4395.

11. Choudalakis, G.; Gotsis, A. D. Permeability of polymer/clay nanocomposites: A review. Eur. Polym. J. 2009, 45, 967-984.

12. Bharadwaj, R. K. Modeling the Barrier Properties of Polymer-Layered Silicate Nanocomposites. Macromolecules 2001, 34, 9189-9192.

13. Ku, B.-C.; Blumstein, A.; Kumar, J.; Samuelson, L. A., Barrier Properties of Ordered Multilayer Polymer Nanocomposites. In Dekker Encyclopedia of Nanoscience and Nanotechnology, Dekker, M., Ed. 2004; pp 213-224.

14. Alexandre, M.; Dubois, P. Polymer-layered silicate nanocomposites: preparation, properties and uses of a new class of materials. Mater. Sci. Eng. R. Rep. 2000, 28, 1-63. 
15. Alix, S.; Follain, N.; Tenn, N.; Alexandre, B.; Bourbigot, S.; Soulestin, J.; Marais, S. Effect of Highly Exfoliated and Oriented Organoclays on the Barrier Properties of Polyamide 6 Based Nanocomposites. J. Phys. Chem. A 2012, 116, 4937-4947.

16. Gorrasi, G.; Tortora, M.; Vittoria, V.; Pollet, E.; Lepoittevin, B.; Alexandre, M.; Dubois, P. Vapor barrier properties of polycaprolactone montmorillonite nanocomposites: effect of clay dispersion. Polymer 2003, 44, 2271-2279.

17. Picard, E.; Gérard, J. F.; Espuche, E. Water transport properties of polyamide 6 based nanocomposites prepared by melt blending: On the importance of the clay dispersion state on the water transport properties at high water activity. J. Membr. Sci. 2008, 313, 284-295.

18. Herrera-Alonso, J. M.; Sedlakova, Z.; Marand, E. Gas transport properties of polyacrylate/clay nanocomposites prepared via emulsion polymerization. J. Membr. Sci. 2010, 363, 48-56.

19. Van Herk, A. M. Historical Overview of (Mini)emulsion Polymerizations and Preparation of Hybrid Latex Particles. Adv. Polym. Sci. 2010, 233, 1-18.

20. Qi, D.; Cao, Z.; Ziener, U. Recent advances in the preparation of hybrid nanoparticles in miniemulsions. Adv. Colloid Interf. Sci. 2014, 211, 47-62.

21. Van Herk, A. M. Polymer Encapsulation of Single Clay Platelets by Emulsion Polymerization Approaches, Thermodynamic, and Kinetic Factors. Macromol. React. Eng. 2016, 10, 22-28.

22. Bourgeat-Lami, E.; Lansalot, M. Organic/Inorganic Composite Latexes: The Marriage of Emulsion Polymerization and Inorganic Chemistry. Adv. Polym. Sci. 2010, 233, 53-123.

23. Bourgeat-Lami, E.; Sheibat-Othman, N.; Dos Santos, A. M., Polymer/clay nanocomposite particles and soap-free latexes stabilised by clay platelets: state of the art and recent advances. In Polymer Nanocomposites by Emulsion and Suspension, Mittal, V., Ed. The Royal Society of Chemistry: UK, 2010; pp 269-311.

24. Bonnefond, A.; Micusik, M.; Paulis, M.; Leiza, J.; Teixeira, R. A.; Bon, S. F. Morphology and properties of waterborne adhesives made from hybrid polyacrylic/montmorillonite clay colloidal dispersions showing improved tack and shear resistance. Colloid Polym. Sci. 2013, 291, 167-180.

25. Voorn, D. J.; Ming, W.; van Herk, A. M. Clay Platelets Encapsulated Inside Latex Particles. Macromolecules 2006, 39, 4654-4656.

26. Reyes, Y.; Paulis, M.; Leiza, J. R. Modeling the equilibrium morphology of nanodroplets in the presence of nanofillers. J. Colloid Interface Sci. 2010, 352, 359-365.

27. Reyes, Y.; Peruzzo, P. J.; Fernandez, M.; Paulis, M.; Leiza, J. R. Encapsulation of Clay within Polymer Particles in a High-Solids Content Aqueous Dispersion. Langmuir 2013, 29, 9849-9856.

28. Mičušík, M.; Bonnefond, A.; Reyes, Y.; Bogner, A.; Chazeau, L.; Plummer, C.; Paulis, M.; Leiza, J. R. Morphology of Polymer/Clay Latex Particles Synthesized by Miniemulsion Polymerization: Modeling and Experimental Results. Macromol. React. Eng. 2010, 4, 432-444.

29. Sun, Q.; Deng, Y.; Wang, Z. L. Synthesis and Characterization of Polystyrene-Encapsulated Laponite Composites via Miniemulsion Polymerization. Macromol. React. Eng. 2004, 289, 288-295.

30. Zengeni, E.; Hartmann, P. C.; Pasch, H. Encapsulation of clay by ad-miniemulsion polymerization: the influence of clay size and modifier reactivity on latex morphology and physical properties. ACS Appl. Mater. Interfaces 2012, 4, 6957-6968.

31. Faucheu, J.; Gauthier, C.; Chazeau, L.; Cavaille, J. Y.; Mellon, V.; Bourgeat-Lami, E. Miniemulsion polymerization for synthesis of structured clay/polymer nanocomposites: Short review and recent advances. Polymer 2010, 51, 6-17.

32. Cenacchi-Pereira, A.; Grant, E.; D'Agosto, F.; Lansalot, M.; Bourgeat-Lami, E., Encapsulation with the use of controlled radical polymerization. In Encyclopedia of Polymeric Nanomaterials, Shiro Kobayashi, K. M., Ed. Springer Berlin Heidelberg: 2015; pp 718-729.

33. Zetterlund, P. B.; Thickett, S. C.; Perrier, S.; Bourgeat-Lami, E.; Lansalot, M. Controlled/Living Radical Polymerization in Dispersed Systems: An Update. Chem. Rev. 2015, 115, 9745-800.

34. Bourgeat-Lami, E.; D’Agosto, F.; Lansalot, M. Synthesis of Nanocapsules and Polymer/Inorganic Nanoparticles Through Controlled Radical Polymerization At and Near Interfaces in Heterogeneous Media. Adv. Polym. Sci. 2016, 270, 123-161.

35. Zhou, J.; Yao, H.; Ma, J. Recent advances in RAFT-mediated surfactant-free emulsion polymerization. Polym. Chem. 2018, 9, 2532-2561. 
36. Mballa Mballa, M. A.; Ali, S. I.; Heuts, J. P. A.; van Herk, A. M. Control of the anisotropic morphology of latex nanocomposites containing single montmorillonite clay particles prepared by conventional and reversible addition-fragmentation chain transfer based emulsion polymerization. Polym. Int. 2012, 61, 861-865.

37. Silva, R. D.; Chaparro, T. d. C.; Monteiro, I. S.; Dugas, P.-Y.; D’Agosto, F.; Lansalot, M.; Martins dos Santos, A.; Bourgeat-Lami, E. Tailoring the Morphology of Polymer/Montmorillonite Hybrid Latexes by Surfactant-Free Emulsion Polymerization Mediated by Amphipathic MacroRAFT Agents. Macromolecules 2019, 52, 4979-4988.

38. Cenacchi-Pereira, A.; Pearson, S.; Kostadinova, D.; Leroux, F.; D'Agosto, F.; Lansalot, M.; Bourgeat-Lami, E.; Prévot, V. Nanocomposite latexes containing layered double hydroxides via RAFT-assisted encapsulating emulsion polymerization. Polym. Chem. 2017, 8, 1233-1243.

39. Pearson, S.; Pavlovic, M.; Augé, T.; Torregrossa, V.; Szilagyi, I.; D’Agosto, F.; Lansalot, M.; Bourgeat-Lami, E.; Prévot, V. Controlling the Morphology of Film-Forming, Nanocomposite Latexes Containing Layered Double Hydroxide by RAFT-Mediated Emulsion Polymerization. Macromolecules 2018, 51, 3953-3966.

40. Li, Y.; Weng, Z.; Pan, Z. Barrier properties of vinylidene chloride/methyl acrylate copolymer. Chinese J. Polym. Sci. 1997, 15, 319-324.

41. Wessling, R. A.; Gibbs, D. S.; Obi, B. E.; Beyer, D. E.; Delassus, P. T.; Howell, B. A., Vinylidene Chloride Polymers. In Kirk-Othmer: Encyclopedia of Chemical Technology, 5 ed.; John Wiley \& Sons: New York, 2007; Vol. 25, pp 691-745.

42. Paquet, C.; Pagé, L.; Kell, A.; Simard, B. Nanobeads Highly Loaded with Superparamagnetic Nanoparticles Prepared by Emulsification and Seeded-Emulsion Polymerization. Langmuir 2010, 26, 5388-5396.

43. Brunier, B.; Sheibat-Othman, N.; Chniguir, M.; Chevalier, Y.; Bourgeat-Lami, E. Investigation of Four Different Laponite Clays as Stabilizers in Pickering Emulsion Polymerization. Langmuir 2016, 32, 6046-6057.

44. The CEC is defined as the number of cations that may be exchanged, expressed as a molar equivalent of electrical charge by mass unity (eq g-1).

45. Sui, Z. M.; Chen, X.; Wang, L. Y.; Xu, L. M.; Zhuang, W. C.; Chai, Y. C.; Yang, C. J. Capping effect of CTAB on positively charged Ag nanoparticles. Physica E. Low. Dimens. Syst. Nanostruct. 2006, 33, 308-314.

46. Zengeni, E. Highly Filled Water Based Polymer/Clay Hybrid Latexes. Thesis from Stellenbosch University, 2012.

47. Bergaya, F.; Lagaly, G., General introduction: Clays, clay minerals, and clay science. In Handbook of clay science, Part A : Fundamentals, 2 ed.; Elsevier, Ed. Newnes: 2013; Vol. 5.

48. Negrete-Herrera, N. Synthesis and characterization of Polymer/Layered silicate nanocomposites by emulsion polymerization using organically-modified synthetic Laponite clay platelets. Thesis from University Claude Bernard Lyon 1, Lyon, 2005.

49. Borsacchi, S.; Geppi, M.; Ricci, L.; Ruggeri, G.; Veracini, C. A. Interactions at the surface of organophilic-modified laponites: a multinuclear solid-state NMR study. Langmuir 2007, 23, 39533960 .

50. He, H.; Ma, Y.; Zhu, J.; Yuan, P.; Qing, Y. Organoclays prepared from montmorillonites with different cation exchange capacity and surfactant configuration. Appl. Clay Sci. 2010, 48, 67-72.

51. Leach, E. S. H.; Hopkinson, A.; Franklin, K.; van Duijneveldt, J. S. Nonaqueous Suspensions of Laponite and Montmorillonite. Langmuir 2005, 21, 3821-3830.

52. Wheeler, P. A.; Wang, J.; Baker, J.; Mathias, L. J. Synthesis and Characterization of Covalently Functionalized Laponite Clay. Chem. Mater. 2005, 17, 3012-3018.

53. Negrete-Herrera, N.; Letoffe, J.-M.; Reymond, J.-P.; Bourgeat-Lami, E. Silylation of laponite clay particles with monofunctional and trifunctional vinyl alkoxysilanes. J. Mater. Chem. 2005, 15, 863-871.

54. This was not considered to be an issue for the purpose of this work as free MPTMS could promote crosslinking during the subsequent emulsion polymerization step, thus favouring the targeted encapsulated morphology.

55. Keddie, J. L.; Routh, A. F., Fundamentals of Latex Film Formation: Processes and Properties. Springer Netherlands: 2010. 
56. Bourgeat-Lami, E.; Farzi, G. A.; David, L.; Putaux, J.-L.; McKenna, T. F. L. Silica Encapsulation by Miniemulsion Polymerization: Distribution and Localization of the Silica Particles in Droplets and Latex Particles. Langmuir 2012, 28, 6021-6031.

57. Negrete-Herrera, N.; Letoffe, J.-M.; Putaux, J.-L.; David, L.; Bourgeat-Lami, E. Aqueous Dispersions of Silane-Functionalized Laponite Clay Platelets. A First Step toward the Elaboration of Water-Based Polymer/Clay Nanocomposites. Langmuir 2004, 20, 1564-1571.

58. Aguirre, M.; Paulis, M.; Barrado, M.; Iturrondobeitia, M.; Okariz, A.; Guraya, T.; Ibarretxe, J.; Leiza, J. R. Evolution of particle morphology during the synthesis of hybrid acrylic/CeO2 nanocomposites by miniemulsion polymerization. J. Polym. Sci. Part A. Polym. Chem. 2015, 53, $792-$ 799.

59. Delafresnaye, L.; Dugas, P.-Y.; Dufils, P.-E.; Chaduc, I.; Vinas, J.; Lansalot, M.; BourgeatLami, E. Synthesis of clay-armored poly(vinylidene chloride-co-methyl acrylate) latexes by Pickering emulsion polymerization and their film-forming properties. Polym. Chem. 2017, 8, 6217-6232.

60. Thompson, D. W.; Butterworth, J. T. The nature of laponite and its aqueous dispersions. $J$. Colloid Interface Sci. 1992, 151, 236-243. 
Innovative method for Laponite encapsulation into polymer latex particles

\section{by clay cluster-seeded emulsion polymerization}

Laura Delafresnaye, ${ }^{\dagger}$ Pierre-Yves Dugas, ${ }^{\dagger}$ Muriel Lansalot,${ }^{{ }^{* *}}$ Elodie Bourgeat-Lami ${ }^{{ }^{* *}}$

${ }^{\dagger}$ Univ Lyon, Université Claude Bernard Lyon 1, CPE Lyon, CNRS, UMR 5265, Chemistry,

Catalysis, Polymers \& Processes (C2P2), 43 Bvd. du 11 Novembre 1918, 69616 Villeurbanne, France.

\section{TOC GRAPHIC}

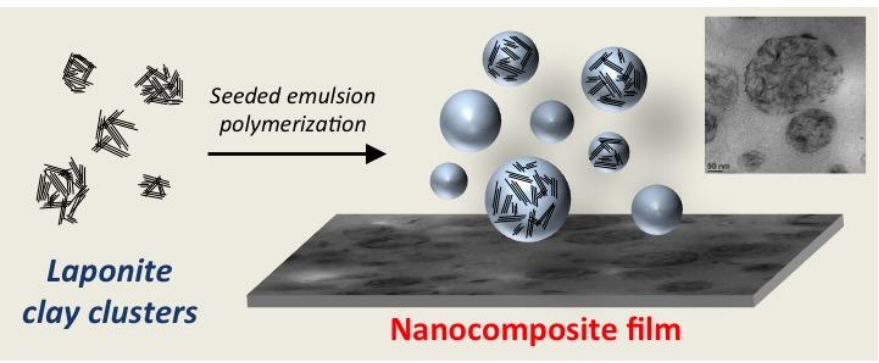

